\title{
The global resurfacing of Venus
}

\author{
Robert G. Strom \\ Department of Planetary Sciences, University of Arizona, Tucson
}

Gerald G. Schaber

Branch of Astrogeology, U.S. Geological Survey, Flagstaff, Arizona

Douglas D. Dawson

Department of Planetary Sciences, University of Arizona, Tucson

\begin{abstract}
The impact cratering record on Venus is unique among the terrestrial planets. Fully $84 \%$ of the craters are in pristine condition, and only $12 \%$ are fractured. Remarkably, only $2.5 \%$ of the craters and crater-related features are embayed by lava, although intense volcanism and tectonism have affected the entire planet. Furthermore, the spatial and hypsometric distribution of the craters is consistent with a completely random one, including stochastic variations. Monte Carlo simulations of equilibrium resurfacing models result in a minimum of 17 times more embayed craters than observed, or unobserved nonrandom crater distributions for resurfacing areas between $0.03 \%$ and $100 \%$ of the planet's surface. These models also are not consistent with the number and nonrandom distribution of volcanoes, and the nonrandom distribution of embayed and heavily fractured craters. The constraints imposed by the cratering record strongly indicate that Venus experienced a global resurfacing event about 300 $m$.y. ago followed by a dramatic reduction of volcanism and tectonism. This global resurfacing event ended abruptly $(<10 \mathrm{~m}$.y.). The present crater population has accumulated since then and remains largely intact. Thermal history models suggest that similar global resurfacing events probably occurred episodically in the past. The tesserae statistically have the same average surface age (crater retention age) as the rest of the planet, but they probably represent older rock units deformed by earlier episodes of global resurfacing. Although they largely survived the latest global resurfacing event, their surfaces were severely deformed by it. Monte Carlo simulations indicate that only about $4 \%-6 \%$ of the planet has been volcanically resurfaced since the global event, and that the lava production rate has been no more than $0.01-0.15 \mathrm{~km}^{3} / \mathrm{yr}$ during this time. This rate is significantly less than the current rate of intraplate volcanism on Earth $\left(0.33-0.5 \mathrm{~km}^{3} / \mathrm{yr}\right)$. Most of Venus' recent volcanism occurs in the Beta-Atla-Themis region, and most of the recent tectonism is associated with the major global-scale tectonic disruption zones that lie within and connect the equatorial highlands. The approximately $33 \%$ of the planet's surface bounded by latitudes $30^{\circ} \mathrm{N}$ and $30^{\circ} \mathrm{S}$, longitudes $60^{\circ}$ and $300^{\circ} \mathrm{E}$ contains twice as many heavily fractured craters and 1.4 times more lava-embayed craters as the planetary average. This region includes most of the major tectonic belts in the equatorial region. Because the craters are indistinguishable from a statistically random distribution, both spatially and hypsometrically, this concentration of strongly fractured and embayed craters is considered indicative of a continuing low level of limited extension and volcanic activity in this region over the past $300 \mathrm{~m}$.y. However, these craters are simply fractured and/or embayed, and very few have been subjected to complete tectonic disruption, complete burial, and subsequent removal from the surface, as was the case during the global resurfacing event. We show that neither the present level and style of geologic activity nor anything less than global resurfacing could have produced the observed cratering record. The effects of recent geologic activity are much less than those of the earlier global resurfacing event, when the record of all the early heavy bombardment and much of the later light bombardment was erased from the surface by massive volcanism and tectonic activity. Episodic regional resurfacing events that had global effects also occurred on Earth (e.g., the mid-Cretaceous superplume) and probably on Mars. On Mars they may have triggered the catastrophic releases of water that formed the outflow channels.
\end{abstract}

Copyright 1994 by the American Geophysical Union.

Paper number 94JE00388.

0148-0227/94/94JE-00388\$05.00 


\section{Introduction}

The impact cratering record on Venus provides important constraints on its resurfacing history and thermal evolution. Based on this cratering record, two different models have been proposed to explain the resurfacing history: (1) equilibrium resurfacing [Phillips et al., 1992] and (2) global resurfacing [Schaber et al., 1992]. Variations of these models have also been proposed. In this paper we examine these models and present new results that strengthen the global resurfacing model originally proposed by Schaber et al. [1992]. We also place constraints on the amount of resurfacing that took place after the global event, and we compare resurfacing styles on Venus and Earth. Some of the results discussed here were presented by Schaber et al. [1992], but they are discussed here in greater detail to better define Venus' resurfacing history and the implications for its thermal evolution. Furthermore, the size and elevation-density distributions of impact craters, impact-related features, crater modification classes, and crater background types are now included in the analyses for $98 \%$ of the planet's surface. Also included is a complete reevaluation of modification classes involving fractured craters based on the now complete multicycle Magellan data set.

\section{Impact Cratering Record}

The impact cratering record consists of four basic components: (1) impact craters and associated ejecta deposits, (2) craterless splotches, (3) haloed craters, and (4) parabolic patterns associated with some craters. Although parabolic patterns are fine-grained crater ejecta, they are deposited by eolian action rather than ballistically emplaced. Impact cratering on Venus is unique in many important ways, particularly in its production of enormous ejecta outflows [Asimow and Wood, 1992; Schaber et al., 1992; Schultz, 1992; Chadwick and Schaber, 1993]. Also, the dense atmosphere of Venus ( 90 bars surface pressure) has had a major influence on the cratering record. It has screened out many impacting objects. It has been the source of shock waves produced by impacting objects which have generated visible effects (splotches or dark shadows) on the surface [Phillips et al., 1992; Schaber et al., 1992; Zahnle, 1992], and it has dispersed fine-grained ejecta downwind to result in parabolic ejecta patterns [Campbell et al., 1992; Vervack and Melosh, 1992].

A total of 932 impact craters have been identified on approximately $98 \%$ of the surface $\left(4.51 \times 10^{8} \mathrm{~km}^{2}\right)$. Table 1 lists the number of craters as a function of diameter for the total crater population, for the various crater types, and for degradational classes. To date, 401 craterless splotches and 58 parabolic patterns have been identified. This impact record constitutes virtually a complete survey of the Magellan mission data.

\section{Crater Distribution}

The impact craters on Venus have a remarkably uniform areal distribution (Figure 1), which Phillips et al. [1992] have shown through statistical analyses to be consistent with a spatially random distribution. S. Emerson (Statistics Department, University of Arizona, Tucson) was asked to perform statistical tests for spatial randomness. He used chi-square tests of the distribution of craters by latitude (actually sine latitude) and longitude for our more complete data set (98\% versus $\sim 85 \%$ of the surface). He compared 5000 Monte Carlo simulations that included 1000 random rotations of 100 equal areas on each of the 5000 simulations. The results show that the pattern of craters on Venus is more "randomly uniform" than about $20 \%$ of the Monte Carlo simulations of random crater distributions. This is a conservative value

Table 1. Venus Impact Crater Data

\begin{tabular}{|c|c|c|c|c|c|c|c|c|c|c|c|c|c|}
\hline \multirow{2}{*}{$\begin{array}{c}\text { Diameter } \\
\text { Range, } \\
\text { km }\end{array}$} & \multirow{2}{*}{$\begin{array}{c}\text { Mean } \\
\text { Diameter, } \\
\text { km }\end{array}$} & \multicolumn{12}{|c|}{ Number of Craters } \\
\hline & & $\begin{array}{c}\text { All } \\
\text { Craters }\end{array}$ & $\begin{array}{c}\text { Class } \\
\mathbf{p}\end{array}$ & $\begin{array}{c}\text { Class } \\
\text { f1 }\end{array}$ & $\begin{array}{c}\text { Class } \\
\text { f2 }\end{array}$ & $\underset{v}{\text { Class }}$ & $\begin{array}{c}\text { Class } \\
\text { c }\end{array}$ & $\begin{array}{c}\text { Type } \\
\text { B }\end{array}$ & $\begin{array}{c}\text { Type } \\
\text { D }\end{array}$ & $\begin{array}{c}\text { Type } \\
\mathbf{P}\end{array}$ & Type & $\begin{array}{c}\text { Type } \\
\text { I }\end{array}$ & $\begin{array}{c}\text { Type } \\
\mathbf{M}\end{array}$ \\
\hline $1.4-2$ & 1.68 & 6 & 6 & & & & & & & & 1 & 3 & 2 \\
\hline $2-2.8$ & 2.38 & 21 & 21 & & & & & & & & 5 & 4 & 12 \\
\hline $2.8-4$ & 3.36 & 31 & 30 & & & & 1 & & & & 4 & 17 & 10 \\
\hline $4-5.6$ & 4.75 & 76 & 67 & 7 & & 2 & & & & 2 & 5 & 44 & 25 \\
\hline $5.6-8$ & 6.72 & 99 & 92 & 3 & 1 & 3 & & & & 1 & 9 & 58 & 31 \\
\hline $8-11.3$ & 9.51 & 140 & 121 & 14 & 2 & 2 & 1 & & & 14 & 32 & 64 & 29 \\
\hline $11.3-16$ & 13.45 & 130 & 106 & 15 & 2 & 7 & & & & 45 & 35 & 42 & 9 \\
\hline $16-22.6$ & 19.02 & 143 & 122 & 11 & 7 & 3 & & & & 90 & 26 & 24 & 4 \\
\hline $22.6-32$ & 26.91 & 123 & 95 & 11 & 11 & 6 & & & & 105 & 5 & 6 & 6 \\
\hline $32-45.2$ & 38.05 & 79 & 58 & 11 & 6 & 4 & & & 6 & 67 & 1 & 2 & 3 \\
\hline $45.2-64$ & 53.81 & 47 & 36 & 5 & 1 & 4 & 1 & & 20 & 23 & 3 & 1 & \\
\hline 64-90.5 & 76.11 & 23 & 19 & 1 & 1 & 2 & & 2 & 13 & 4 & 3 & 1 & \\
\hline $90.5-128$ & 107.63 & 9 & 7 & & 2 & & & & 9 & & & & \\
\hline $128-181$ & 152.22 & 3 & 3 & & & & & 3 & & & & & \\
\hline $181-256$ & 215.27 & & & & & & & & & & & & \\
\hline $256-362$ & 304.44 & 1 & 1 & & & & & 1 & & & & & \\
\hline Total & & 931 & 784 & 78 & 33 & 33 & 3 & 6 & 48 & 351 & 129 & 266 & 131 \\
\hline
\end{tabular}

*Area counted is 451.04 million $\mathrm{km}^{2}$ which is equal to $98 \%$ of surface. One crater could not be measured or assigned a type because of a partial imaging gap. Class $p$, pristine; class $\mathrm{f} 1$, lightly fractured; class $\mathrm{f} 2$, heavily fractured; class $\mathrm{v}$, lava embayed; class $c$, transected by compressional ridges; type $B$, multiple rings; type $D$, double rings; type $P$, central peak; type $\mathrm{S}$, no floor structure; type I, irregular crater; type $\mathrm{M}$, multiple crater. 


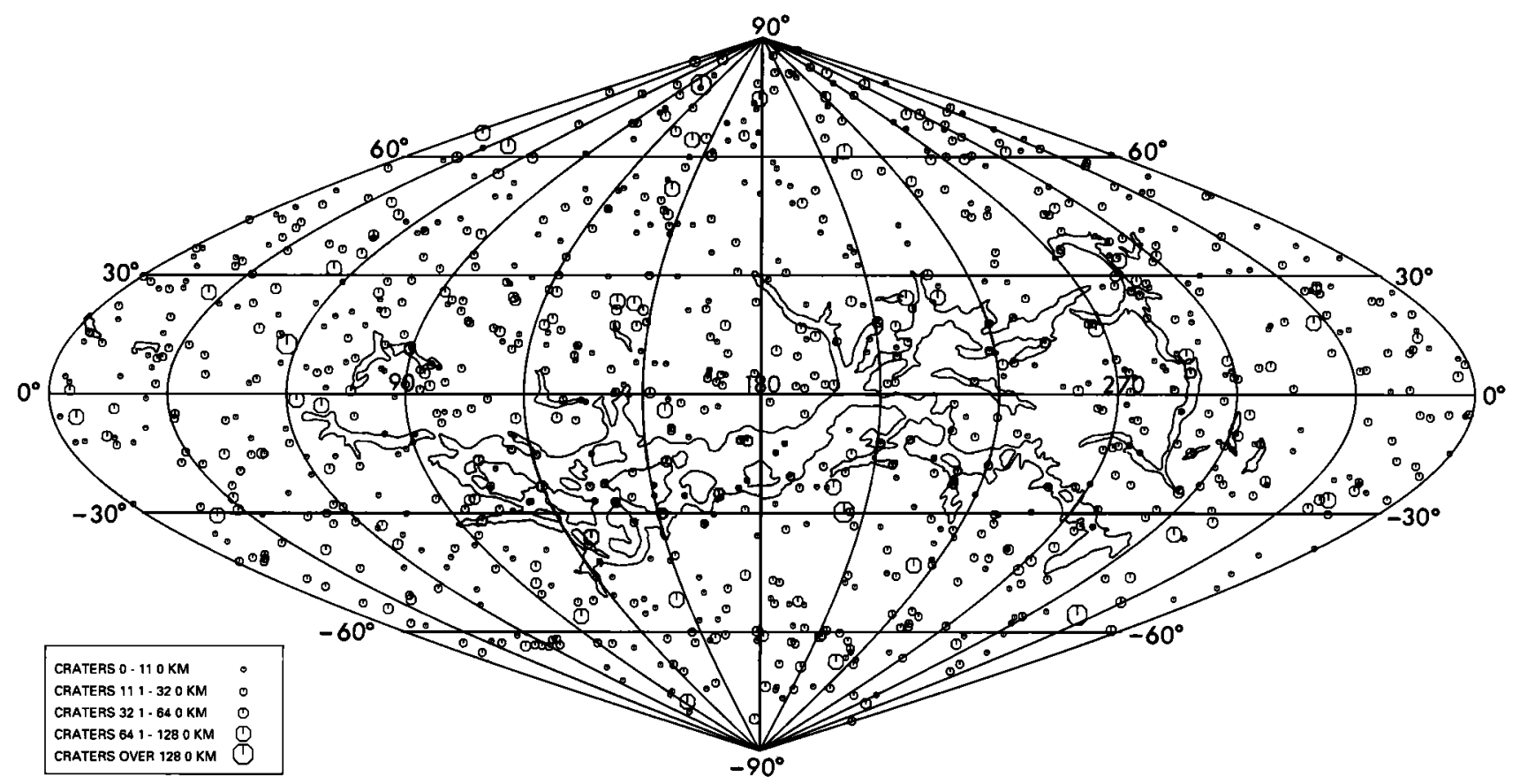

Figure 1a. Map in sinusoidal equal-area projection showing the sizes and distribution of the 932 impact craters on $98 \%$ of Venus' surface. Sizes of symbols are scaled to crater diameter bins but not to map. Shaded areas indicate fracture belts of concentrated extensions (modified from Schaber [1982] using Magellan data).

because the comparisons assumed $100 \%$ coverage of Venus and did not take into account the gaps $(2 \%)$ in the coverage. Emerson therefore concludes that the Venus crater population cannot be distinguished from a spatially random distribution. Figure 2 shows five Monte Carlo simulations of spatially random point (932) distributions in cylindrical projection together with the observed crater distribution on Venus in the same projection. It is virtually impossible to distinguish between them, and the figure visually supports the Venus random distribution determined by Phillips et al. [1992] and ourselves using more rigorous statistical tests. Also note the "clusters" and "gaps" in the distributions that are solely the result of stochastic variations in random distributions of low density. This random distribution accounts for the overall constancy of the size/density distribution from area to area, including that in diverse geological

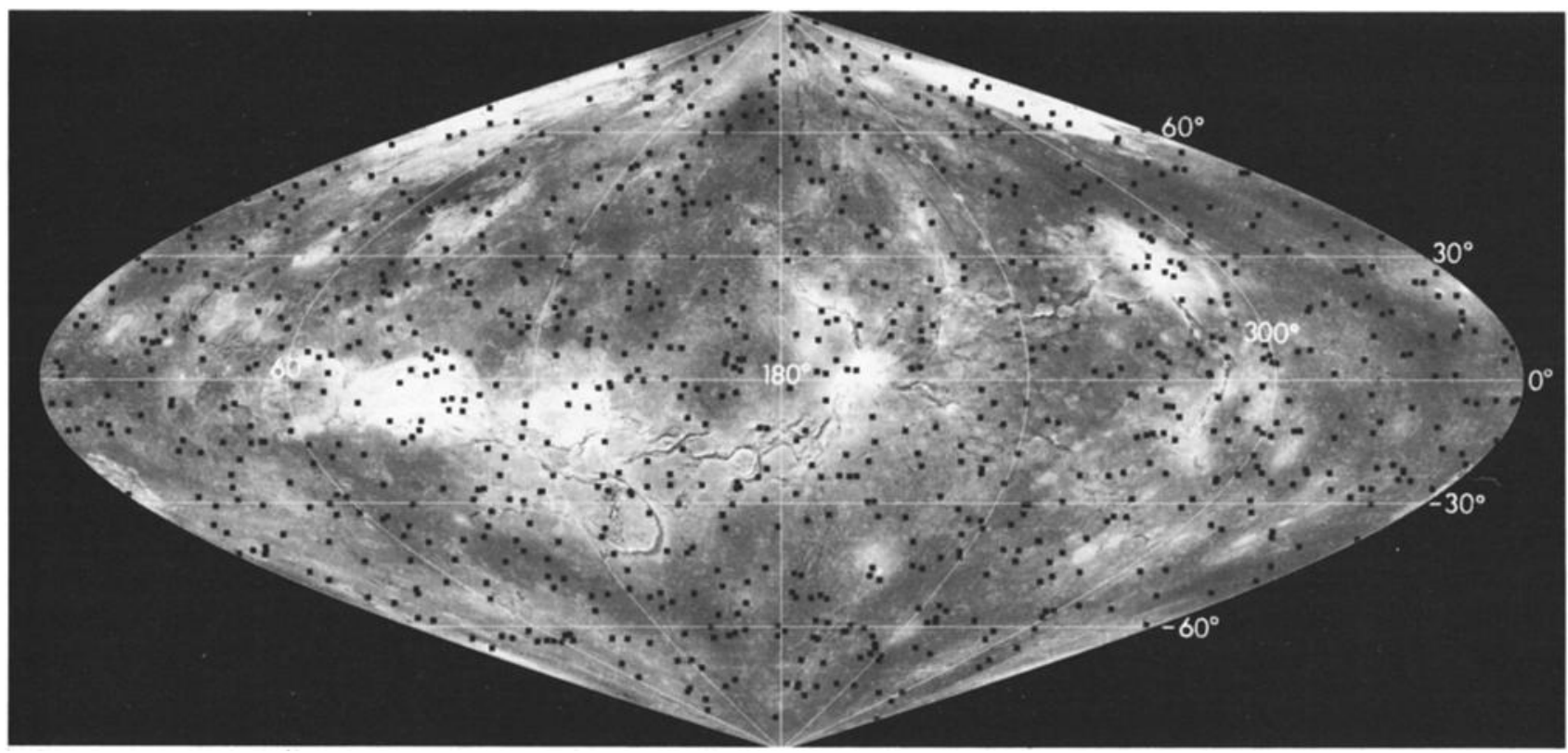

Figure 1b. Sinusoidal equal-area altimetric map of Venus showing the distribution of all impact craters. Brighter areas are higher than darker areas. 

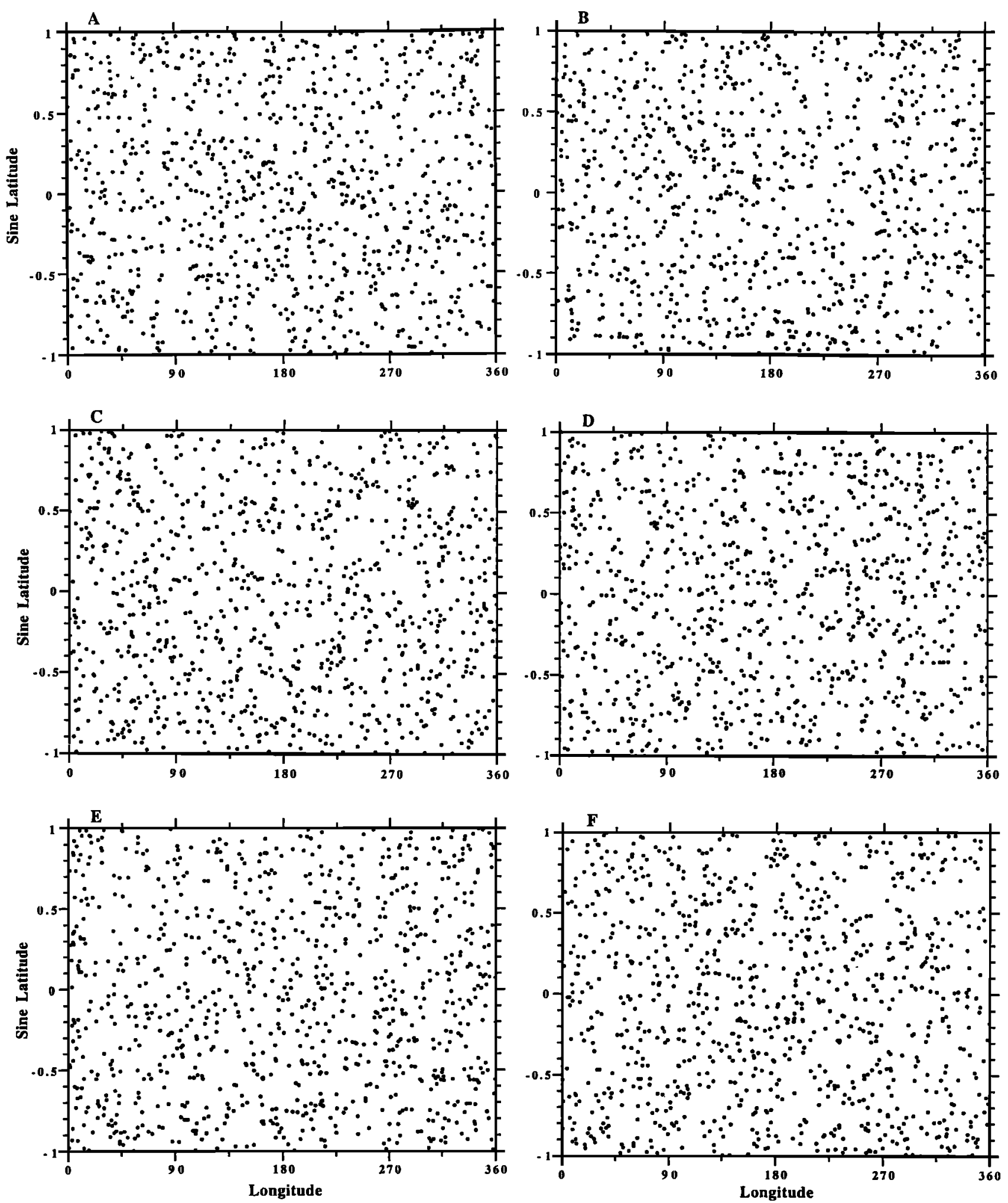

Figure 2. Cylindrical projections of five Monte Carlo simulations of 932 spatially random points compared to the distribution of the 932 craters on $98 \%$ of Venus. Note the "clusters" and "holes" due to stochastic variations. Venus is shown in panel B (some "holes" due to gaps (2\%) in coverage).

provinces [Schaber et al., 1992] (see also Figure 13). Neither the Moon nor any terrestrial planet exhibits a spatially random crater distribution because of (1) different ages and intensities of resurfacing events and (2) variations in the size/density distribution due to different resurfacing and erosional processes at different times.

The craters also have a uniform distribution with respect to elevation. The histogram of Figure 3 shows no more than 


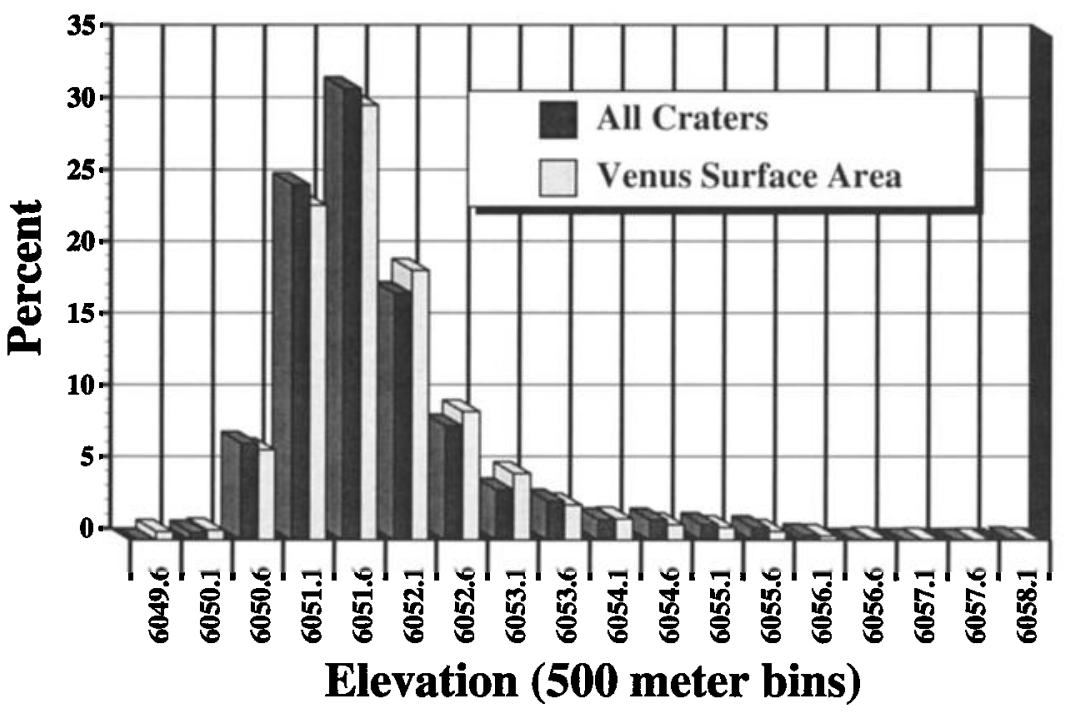

Figure 3. Histogram showing the percentage of impact craters compared to the percentage of surface area in 500-m elevation bins. Statistical tests indicate that the craters are randomly distributed with respect to elevation (see text for details).

a $1.6 \%$ difference between the percentage of craters and the percentage of surface area in any $500-\mathrm{m}$ bin containing a crater (see also Figure 1b). Multinomial chi-square statistical tests of the data set were performed by $S$. Emerson. In these tests, probability values ( $P$ values) greater than 0.05 show "no evidence against a random distribution" of craters with respect to elevation. The $P$ value for all categories of altitude is $\mathbf{0 . 1 7}$. However, this test is not as reliable because the five highest altitude categories contain too few craters per category. To achieve statistical stability, the five highest altitude categories were combined, and the observed, expected, difference and "normalized difference" for altitude categories were compared. This is statistically more trustworthy and yields a $P$ value of 0.31 . Thus both tests indicate that there is "no evidence against a random distribution," the more reliable test indicating a greater probability of randomness. These results are not in agreement with an earlier report of possible ancient terrains on Venus [Schultz, 1993] or crater density variations of about $10 \%$ within $2-\mathrm{km}$ elevation bands [Herrick, 1993]. Our results support a remarkably random distribution of craters with elevation and agree with the observed spatially random distribution of the crater population. Therefore, on average, the highlands and lowlands have the same crater density and age. In reality, there are surely age differences within each Venusian terrain that can be determined by stratigraphic relations, but the correspondence in average ages suggests that the differences are not great on an absolute timescale. Even recent activity (discussed later) has not had a statistically significant effect on the crater population, which remains largely intact since it was formed. As discussed below, it is not possible to determine relative or absolute ages of local or regional areas by crater densities because the crater population has a spatially and hypsometrically random distribution with stochastic variations.

The random distribution of Venusian craters is independent of size: small craters are as randomly distributed as large ones [Phillips et al., 1992; Schaber et al., 1992]. On other planets and satellites, small craters have been prefer- entially obliterated with respect to large craters by various resurfacing processes. This results in a dearth of small craters in some areas compared to others. On Venus, small craters have not been preferentially obliterated with respect to large craters, suggesting that resurfacing has been negligible since the craters were formed.

Areas of seemingly low or high crater densities may result from stochastic processes in a statistically random distribution (Figure 4), particularly at the low crater density of Venus (about 1 crater per $500,000 \mathrm{~km}^{2}$ ). In fact, Phillips et al. [1992] and Emerson (see above) have shown that the observed patchiness in crater density cannot be distinguished from that generated by Monte Carlo simulations. Such patchiness is illustrated by the "clusters" and "holes" in the random crater distributions generated by our Monte Carlo simulations shown in Figure 2.

Because impact craters on Venus cannot be distinguished from a random distribution, both spatially and hypsometrically (Figures 2 and 3), relative and absolute dating of local or regional terrains based solely on crater densities is statistically impossible. This is especially true due to stochastic effects in a random crater distribution of low density, as discussed above. Thus the cratering record along with an appropriate cratering rate can be used only to estimate the average absolute age of the entire planetary surface [Schaber et al., 1992]. Stratigraphic methods are the only reliable way of determining age differences on Venus. Crater densities cannot be used to derive absolute age differences because of possible stochastic effects. On Venus, only the embayed and highly fractured craters are correlated with concentrations of volcanic or tectonic structures, thus indicating more recent activity. Despite this, three regions on Venus (covering $25 \pm$ $10 \%$ of the surface) with proposed distinct surface ages have been reported by Phillips [1993] and Herrick [1993], who considered presumed crater density variations along with other factors, and shown in Figure 3 of Solomon [1993a]. Ivanov and Basilevsky [1993] also proposed age differences between tesserae and other terrains based on differences in crater densities. We discuss these studies later in the paper. 


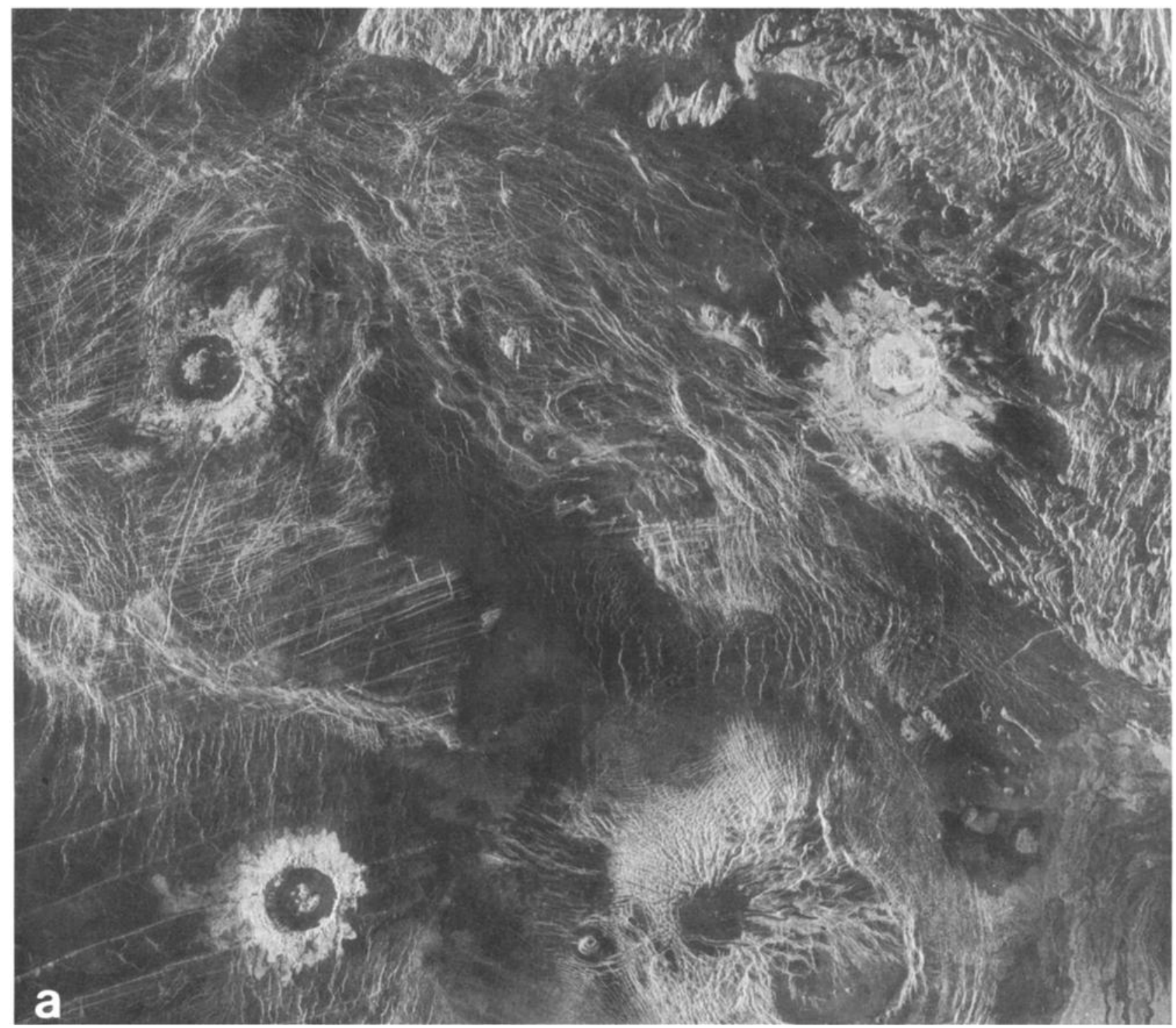

Figure 4. Two examples of probable stochastic concentrations of craters on Venus. (a) Three large craters in about $332,000 \mathrm{~km}^{2}$, which is 4.4 times more than the average global density of about 1 per $5 \times$ $10^{5} \mathrm{~km}^{2}$. (b) Nine craters and one splotch in about $1,650,000 \mathrm{~km}^{2}$, which is 2.7 times the global average (Magellan images (a) F-70N296 and (b) Cl-45N138).

\section{Crater Size/Density Distribution}

Venus' crater size/density distribution also differs markedly from that of other planets and satellites. (See, for example, the $R$ plot of Figure 5. $R$ plots are log-log plots of crater density normalized to a typical slope [Crater Analysis Techniques Working Group, 1979]. $R$ is constant for a differential size-frequency distribution proportional to $D^{-3}$ (cumulative distribution proportional to $D^{-2}$ ). Idealized crater size-frequency distributions are typically proportional to $D^{-n}$, where $2 \leq n \leq 4$, so they plot as horizontal or gently sloping lines on an $R$ plot, and actual crater densities, as well as any deviations from strict power law behavior, are readily evident. For convenience, an $R$ value is simply referred to as "size/density," and the curve of $R$ values as size/density distribution. Crater statistics of younger surfaces are more reliable on Mars than on the Moon and Mercury because of the wide range in surface ages and because the larger counting areas result in greater numbers of craters [Strom et al., 1992]. The crater size/density distributions on the younger Martian surfaces have a differential -3 slope (cumulative -2 ) at diameters greater than $600 \mathrm{~m}$ (Figure 5). It is estimated that on Mars, asteroidal impacts are about 5-10 times more frequent than comet impacts [Basaltic Volcanism Study Project, 1981]. Therefore this size/density distribution probably represents primarily asteroidal impacts [Strom et al., 1992]. On Venus, at diameters greater than about $35 \mathrm{~km}$, the crater size/density distribution also has a differential -3 slope, in agreement with young production surfaces on Mars (Figure 5) and the Moon. This part of the size/density distribution has not been affected by atmospheric screening and represents the size distribution of objects that collided with Venus. The crater density, however, is very low, about 3 times lower than the Tharsis plains of Mars, one of the most sparsely cratered 


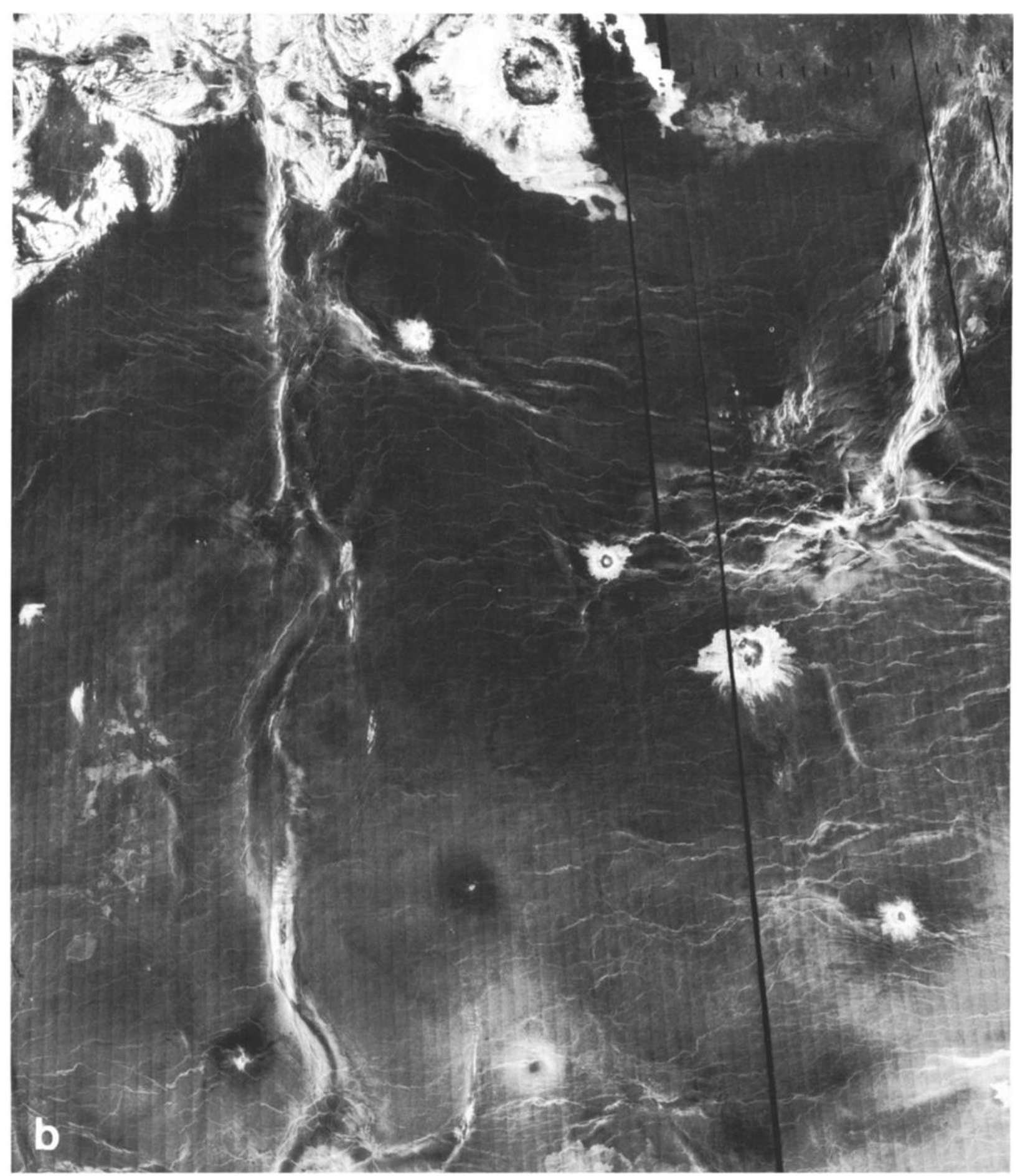

Figure 4. (continued).

areas of the inner planets (Figure 5). All craters dating from the period of late heavy bombardment that ended about 3.8 b.y. ago have been destroyed by endogenic activity, and many craters representing impacts in the post-heavy bombardment era have also been destroyed.

At crater diameters less than about $35 \mathrm{~km}$ there is an increasing loss of craters with decreasing diameter relative to a differential -3 slope (Figure 5 ). No primary craters less than $1.5 \mathrm{~km}$ in diameter have been identified, although craters less than $500 \mathrm{~m}$ in diameter could be readily detected at the Magellan radar resolution of $75 \mathrm{~m}$ per pixel. This progressive loss of craters is probably the result of screening by the dense atmosphere [Phillips et al., 1992; Schaber et al., 1992; Zahnle, 1992]. It is estimated that more than 43,000 objects failed to form craters between 2 and $32 \mathrm{~km}$ in diameter (46 times the number actually observed) since the 


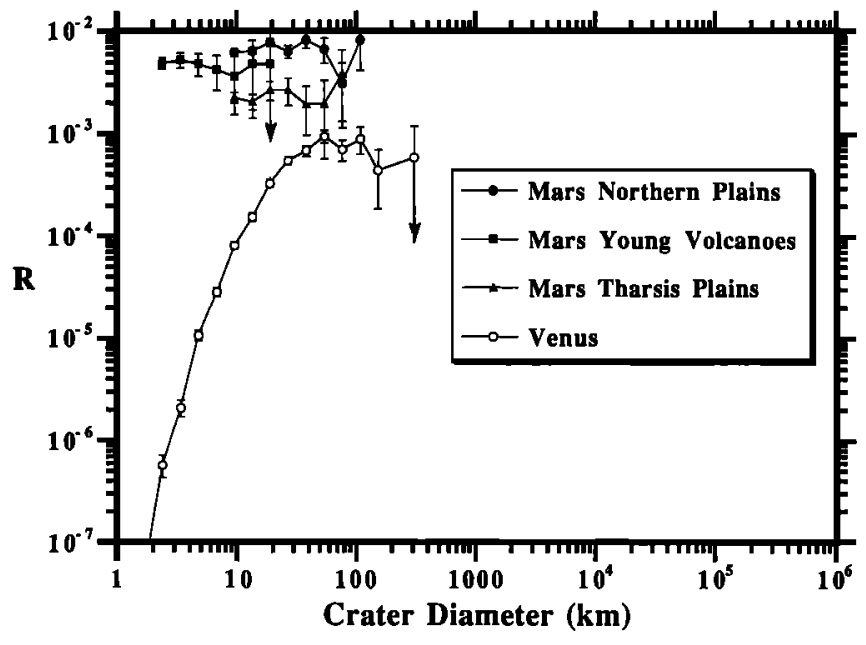

Figure 5. $R$ plot showing impact crater size/density distribution for Venus compared to those for "young" surfaces on Mars. See text for definition of $R$ plot.

present cratering record began some $300 \mathrm{~m} . \mathrm{y}$. ago [Schaber et al., 1992]. About 400 of these objects are responsible for the craterless splotches discussed below.

\section{Crater Modification}

Another unique characteristic of Venusian craters is their remarkably pristine condition. On other terrestrial planets and satellites, craters exhibit a broad range of degradational states, from barely discernible rims to fresh morphologies with well-defined rims and ejecta blankets. The degradational states of these craters are due to a combination of atmospheric erosion and deposition (Earth and Mars), fluvial and glacial erosion and deposition (Earth and Mars), volcanic burial (Moon, Mercury, and Mars), and impact gardening (Moon, Mercury, and Mars). Except on Earth, tectonism has played a relatively minor role in crater degradation. On Venus there is little evidence of crater degradation except by simple fracturing and embayment by volcanic deposits. We show below that these processes have been highly regional since the present cratering record began to form. Unlike the slow, systematic degradation, for example, of all lunar craters by impact [Wilhelms, 1987], the modification of Venusian craters by recent tectonic and volcanic activity is clearly not consistent planetwide. Crater degradation on Venus is, in fact, strongly dependent on where the crater is located on the planet (see section below on postglobal resurfacing activity). First-order models for impact crater degradation on Venus have, however, been proposed [Izenberg et al., 1993a, b].

A complete reassessment of the modification classes of all slightly and heavily fractured craters on Venus has been accomplished since our preliminary report [Schaber et al., 1992]. Our earlier classification, based solely on partial Magellan cycle 1 data and limited full-resolution coverage, was found to seriously underestimate the percentage of pristine craters, and overestimate the percentage of craters that are fractured. A new methodology for classifying fractured crater modification made use of all images from mapping cycles 1,2 , and 3 (obtained at different look directions). Craters were classified as fractured only if one or more fractures clearly transect the crater rim and the crater floor. Because crater floors on Venus are commonly flat and image dark, this provides a good contrast in radar backscatter with crosscutting, radar-bright fractures. We believe this new criterion for classification of fracture modification levels much more accurately reflects the number of craters clearly modified by simple fracturing than the criterion used earlier, where all subtle lineaments on the crater floor, wall, or ejecta were considered as potential (but rarely certain) fractures. Close examination of the entire Magellan data set showed that many fractures that earlier appeared to transect the crater ejecta or walls, for example, did not cross the floor deposits. These features were, in fact, preexisting structures only thinly blanketed by ejecta. This is especially troublesome for craters on topographically complex surfaces (e.g., tesserae) that are radar rough and image bright. An example of a crater previously classified as heavily fractured, and now classified as pristine, is shown in Figure 6.

A remarkable $84 \%$ of the craters (Table 1 and Figure 7a) are now classified as having pristine morphologies (compared to the $62 \%$ reported earlier by Schaber et al. [1992]). Only $8.5 \%$ of the craters have been slightly fractured (f1), and only $3.5 \%$ show clear evidence of having been heavily fractured ( $f$ ) (Table 1). The lightly fractured craters are widely distributed, while the more heavily fractured and lava-embayed craters are not (Figures $7 b-7 d)$. Furthermore, only three craters (all in the southern hemisphere) appear to be transected by compressive wrinkle ridge structures. There is no evidence that the thick atmosphere has played anything but a minor role in crater degradation, although fine-grained ejecta have been affected by eolian action.

Compared with other planets and satellites, Venus has an unusually low percentage of lava-embayed craters. Only 33 out of 932 craters $(3.4 \%$ ) have had some part of their rim materials embayed by lava flows (Figure 7d). This is one of the most remarkable characteristics of the cratering record on Venus, considering the widespread (virtually global) distribution of volcanic landforms [Head et al., 1992]. Some craters may have lava-flooded floors, possibly the indirect result of an impact that allowed lava to reach the floors through impact-generated fractures beneath the crater. However, radar-dark floored craters may simply be smooth impact melt. Radar-bright floors that are probably impact melt often show the same type of wall and central peak stratigraphic relationships as dark floors. As mentioned above, the heavily fractured and embayed craters are not randomly distributed (Figures $7 \mathrm{c}$ and $7 \mathrm{~d}$ ). Global tensional stresses have apparently dominated the crust, and these stresses have been concentrated in the equatorial rift zones and fracture belts that cover about $33 \%$ of the planet and contain the most heavily fractured craters and a concentration of the lava-embayed craters. The only other recognized concentration of heavily fractured craters lies north of $45^{\circ} \mathrm{N}$ latitude. Unlike the complete Venus crater inventory, the hypsometric and spatial distributions of fractured and lavaembayed impact craters are not consistent with a random one. We find, in general agreement with Herrick [1993], that the mean elevation of the heavily fractured craters is highest $(6052.86 \pm 2.03 \mathrm{~km})$, followed by slightly fractured craters $(6052 \pm 1.50 \mathrm{~km})$, and lava-embayed craters $(6052.17 \pm 0.83$ $\mathrm{km})$. The much more abundant pristine craters have a significantly lower mean elevation of $6051.74 \pm 0.83 \mathrm{~km}$. These differences in mean elevation between pristine and geologically modified craters are expected because the 


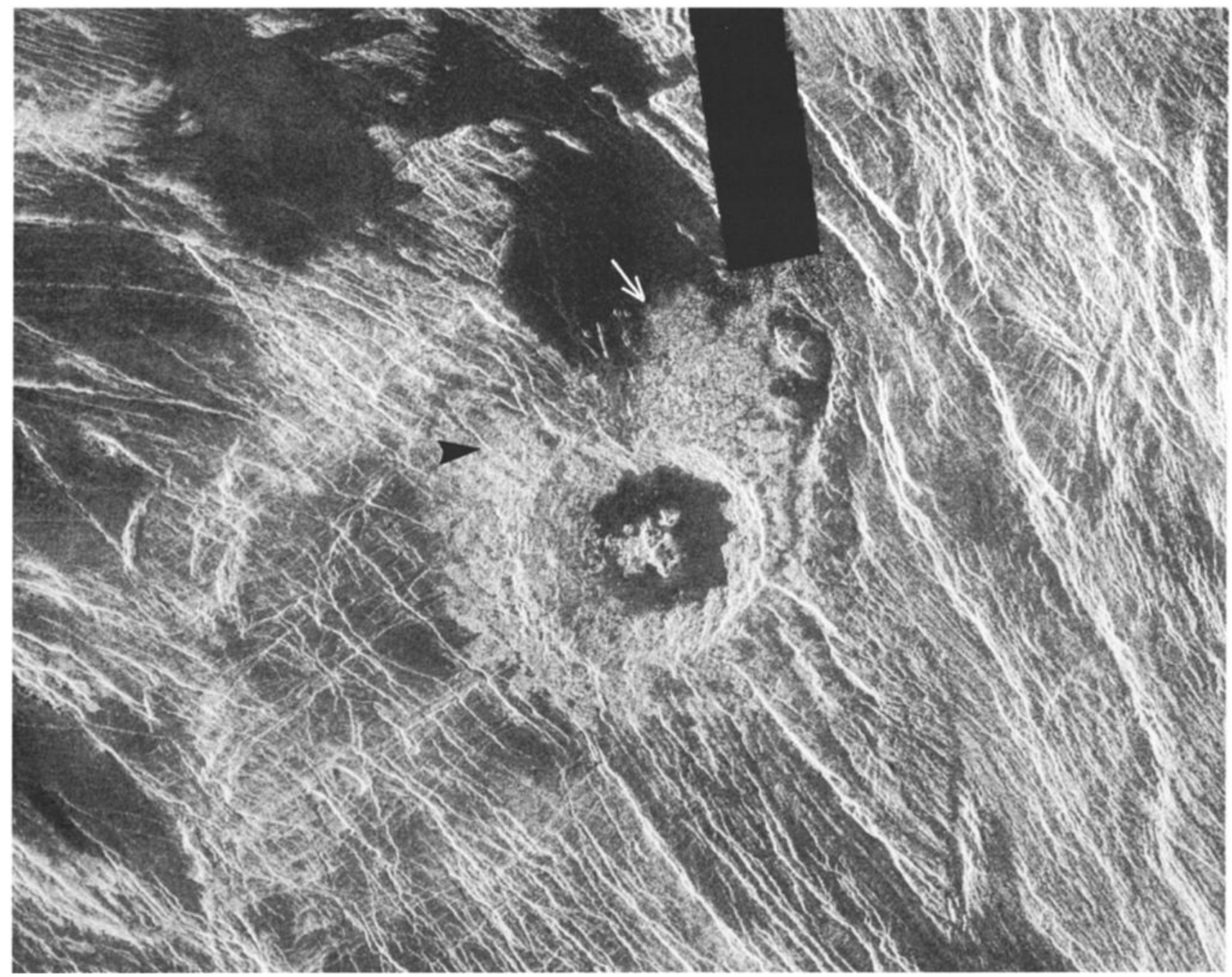

Figure 6. This crater (Zhu Shuzhen, $29.5 \mathrm{~km}$ diameter; latitude $26.5^{\circ} \mathrm{S}$, longitude $356.5^{\circ} \mathrm{E}$ ) was previously classified as heavily fractured but has been reclassified as pristine because the fractures extending to the rim do not cross the floor. Furthermore, the radar-dark material that embays the fractured terrain, on which the crater lies, is overlain by the crater's ejecta (white arrow) but it is not crossed by the fracture set that runs up to the crater rim. Also, at least one fracture (black arrow) that seems to transect the ejecta blanket is covered by ejecta closer to the crater rim. These relationships indicate that the crater postdates the fracturing and that the ejecta blanket is just too thin in most areas to cover the fractures. It is also possible that the impact itself reactivated some of the faults (Magellan image F-25S357).

present low level of geologic activity on Venus is concentrated primarily along the equatorial highlands and associated with fracture belts (see section below on postglobal resurfacing activity). We disagree with Herrick [1993] that the distribution of the total crater population is distinctly nonrandom with elevation (see previous section).

\section{Average Surface Age}

The average age of the surface can be derived from estimates of the crater production rate at Venus for the current collision rates of observed Venus-crossing asteroids. An average age of $500 \mathrm{~m} . \mathrm{y}$. was adapted for convenience by Schaber et al. [1992] based on the cratering record for $89 \%$ of the planet. More recently, Shoemaker et al. [1991] and E. M. Shoemaker (personal communication, 1993) estimate that the crater production rate at Venus is $1.07 \pm 0.6 \times 10^{-15}$ $\mathrm{km}^{-2} \mathrm{yr}^{-1}$ for craters $\geq 35 \mathrm{~km}$ in diameter and $1.29 \pm 0.6 \times$
$10^{-15} \mathrm{~km}^{-2} \mathrm{yr}^{-1}$ for craters $\geq 32 \mathrm{~km}$ in diameter. These estimates take into account corrections for deceleration, impact speed, and cratering efficiency. A total of 147 craters $\geq 35 \mathrm{~km}$ in diameter and 162 craters $\geq 32 \mathrm{~km}$ in diameter have been counted on $4.46 \times 10^{8} \mathrm{~km}^{2}$ of Venus' surface. Averaging the age results from these two diameter ranges gives an average surface age of $288(+311,-98) \mathrm{m}$.y. Therefore the average surface age could be as young as $190 \mathrm{~m}$.y. or as old as $600 \mathrm{~m} . \mathrm{y}$. For these estimates, we assume that comets have made only a minor contribution to the cratering record on Venus for crater diameters $>32 \mathrm{~km}$. Computer simulations by Ivanov et al. [1992] indicate that some comets as small as $1 \mathrm{~km}$ in diameter could form craters on Venus. If cometary impact craters comprise a significant portion of the craters $>32 \mathrm{~km}$ in diameter, then the average surface age could be younger than estimated above. However, for the analyses and discussions that follow, we adopt an average 


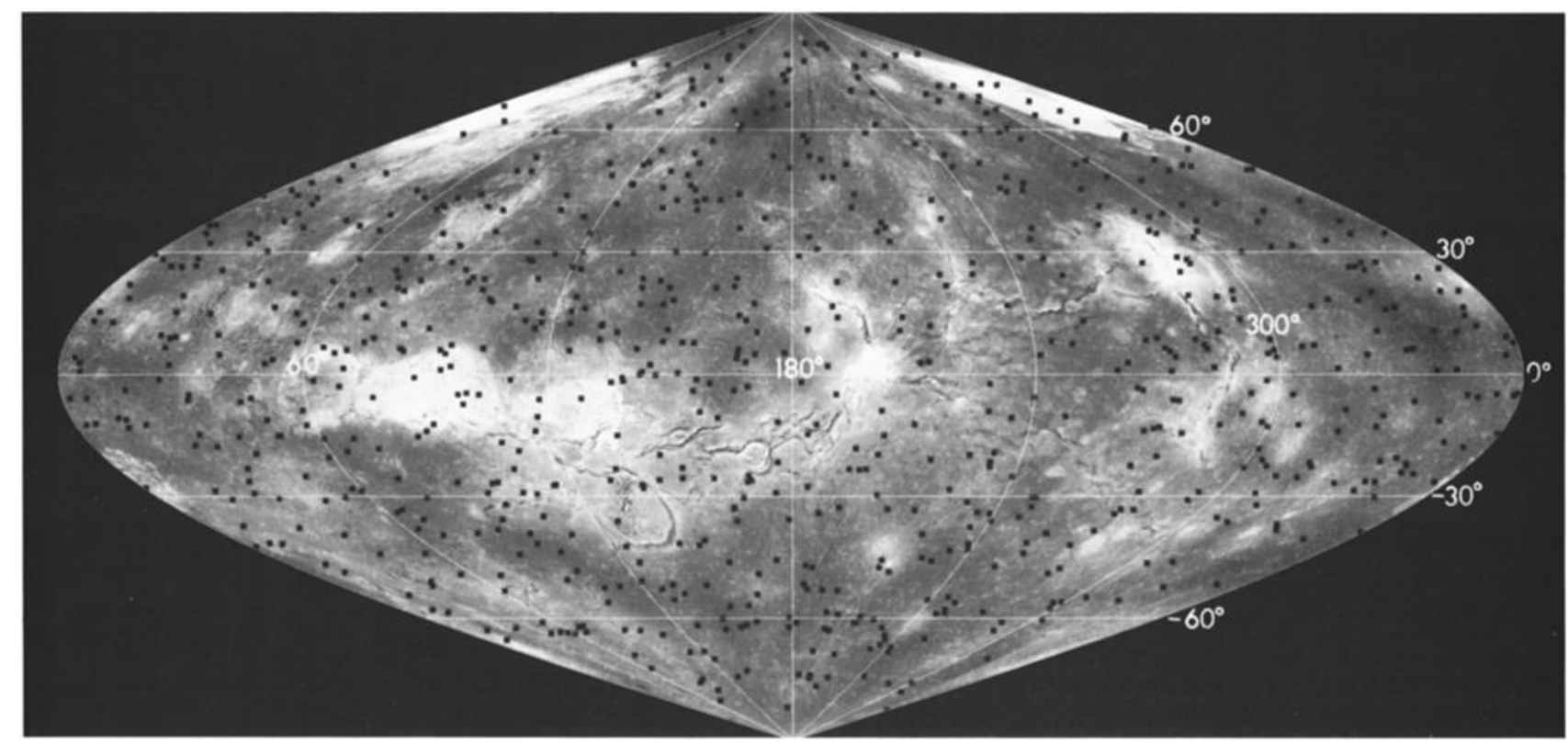

Figure 7a. Sinusoidal equal-area altimetric maps of Venus showing the distribution of pristine craters.

surface age for Venus of 300 m.y., keeping in mind the large uncertainty.

\section{Crater-Related Features}

Craterless splotches. These features form an integral part of the impact record on Venus. They consist of diffuse light and/or dark markings $7-500 \mathrm{~km}$ in diameter. They are interpreted to be the surface expression of atmospheric shock waves transmitted to the surface from air blasts generated by the disruption of impactors in the dense atmosphere [Phillips et al., 1992; Schaber et al., 1992; Zahnle, 1992]. To date, 401 of these features have been identified. Virtually none have been clearly embayed by lavas. Thus the total number of impact-related surface markings (craters and craterless splotches) is 1333 over $98 \%$ of the planet's surface. Therefore only $2.5 \%$ of all impact-related features have been embayed by lava.

Craterless splotches are not randomly distributed (Figure 8). They occur in clusters primarily in the topographically lower plains regions, and they are notably absent on rough terrain, e.g., tesserae. They have apparently not formed or are not detectable on rough terrain and/or at higher elevations. If the density of splotches in the plains regions is typical of the number of objects that entered the atmosphere but did not produce detectable splotches elsewhere, then about 1100 such objects entered the atmosphere over the

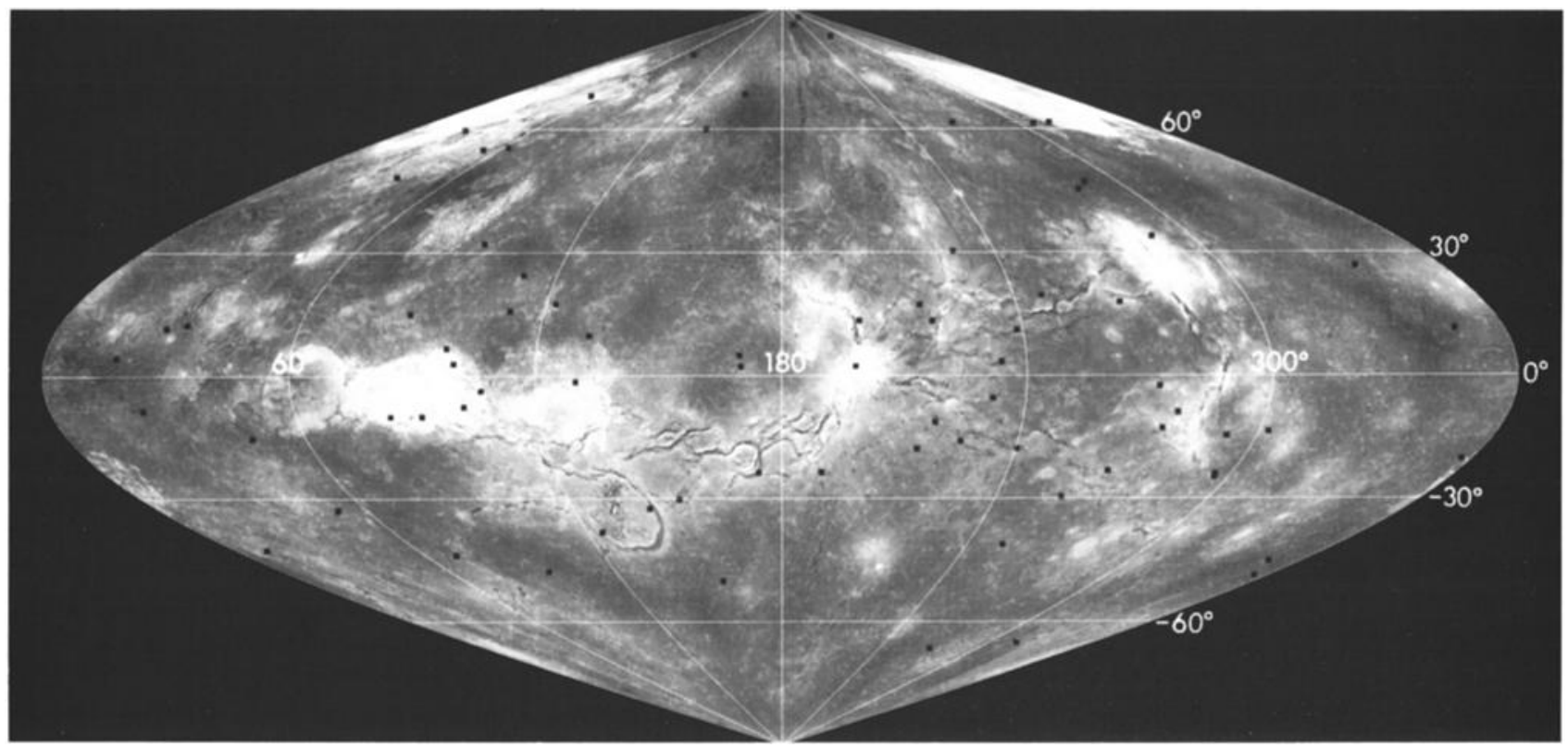

Figure 7b. Same as Figure 7a but showing slightly fractured craters. 


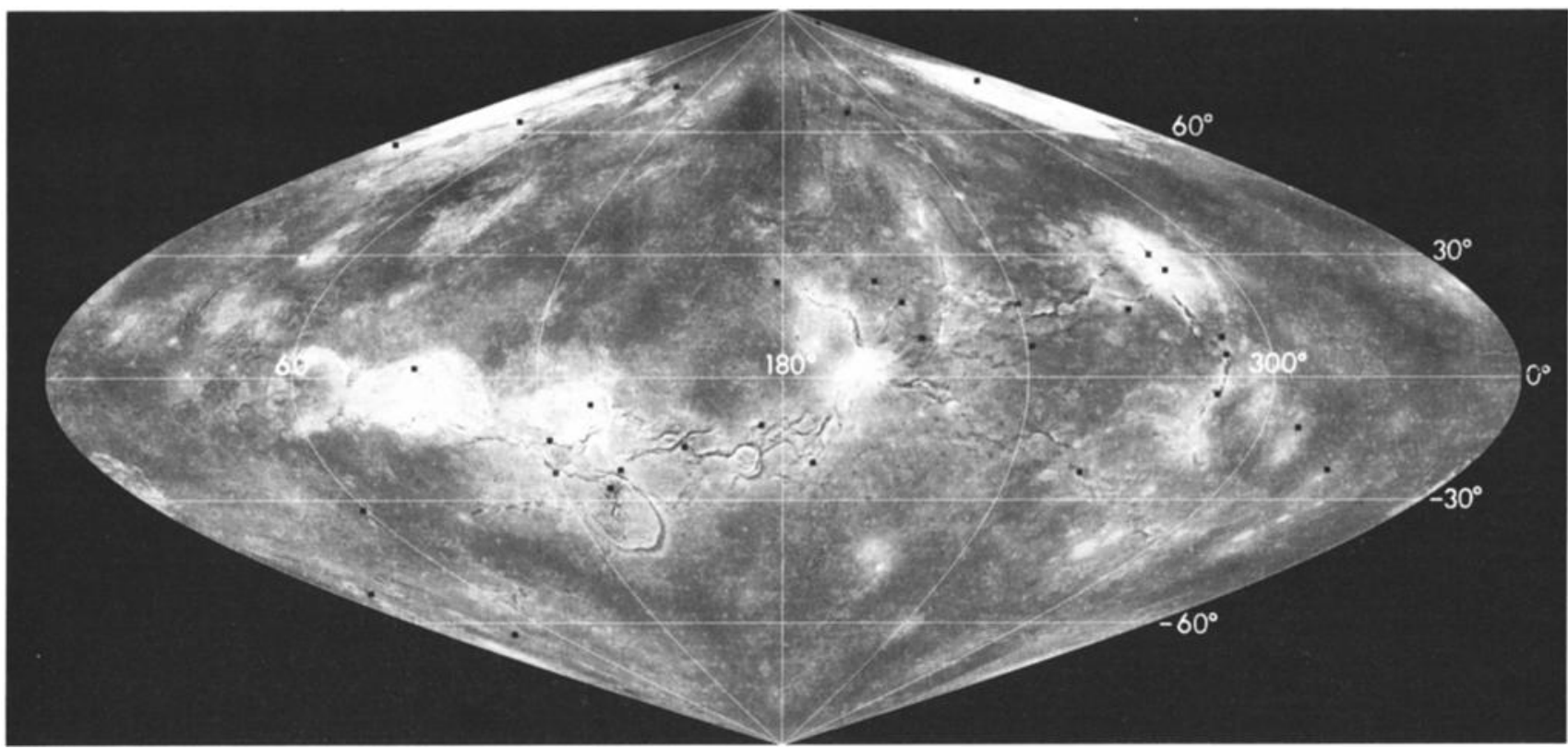

Figure 7c. Same as Figure 7a but showing heavily fractured craters.

average age of the surface. Thus about 2000 objects may have been responsible for the observed craters, splotches, and unrecorded splotches. This number is much less than the 43,000 objects capable of forming craters between 2 and 32 $\mathrm{km}$ in diameter estimated to have impacted Venus over the average age of the surface, suggesting that only the larger objects are capable of forming splotches. Extrapolating downward along a differential -3 slope gives 2000 objects at an equivalent crater diameter of about $8 \mathrm{~km}$, which suggests that on average, only objects large enough to produce craters greater than about $\mathbf{8 k m}$ in diameter are capable of producing splotches.

The size/density distribution for maximum diameters of craterless splotches is similar to the crater size distribution, but it is shifted to higher densities at larger diameters (Figure 9). The higher density is, of course, due to the existence of more large splotches than similar-sized craters. The loss of splotches occurs at diameters less than about $100 \mathrm{~km}$, whereas for craters the loss occurs at about $35 \mathrm{~km}$. This difference may result from a combination of the impact and physical properties of asteroids and comets [Chyba et al., 1993; Hills and Goda, 1993; Zahnle, 1992], such as density, composition (icy comets, stony, iron, or stony iron asteroids), impact velocity and entry angle, and physical state (solid or highly disrupted [Greenberg et al., 1994]).

Haloed craters. Haloed craters have dark or light diffuse

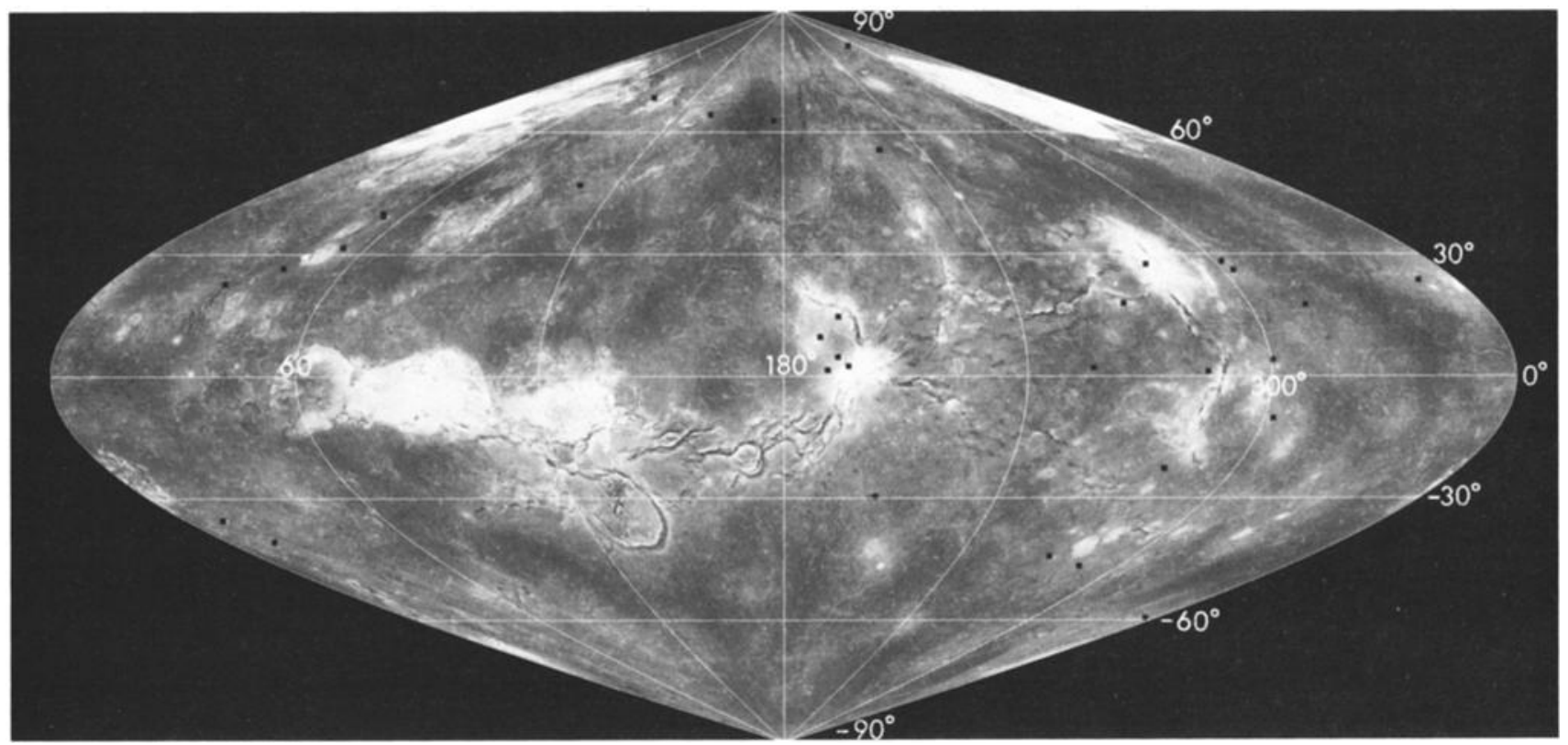

Figure 7d. Same as Figure 7a but showing volcanically embayed craters. 


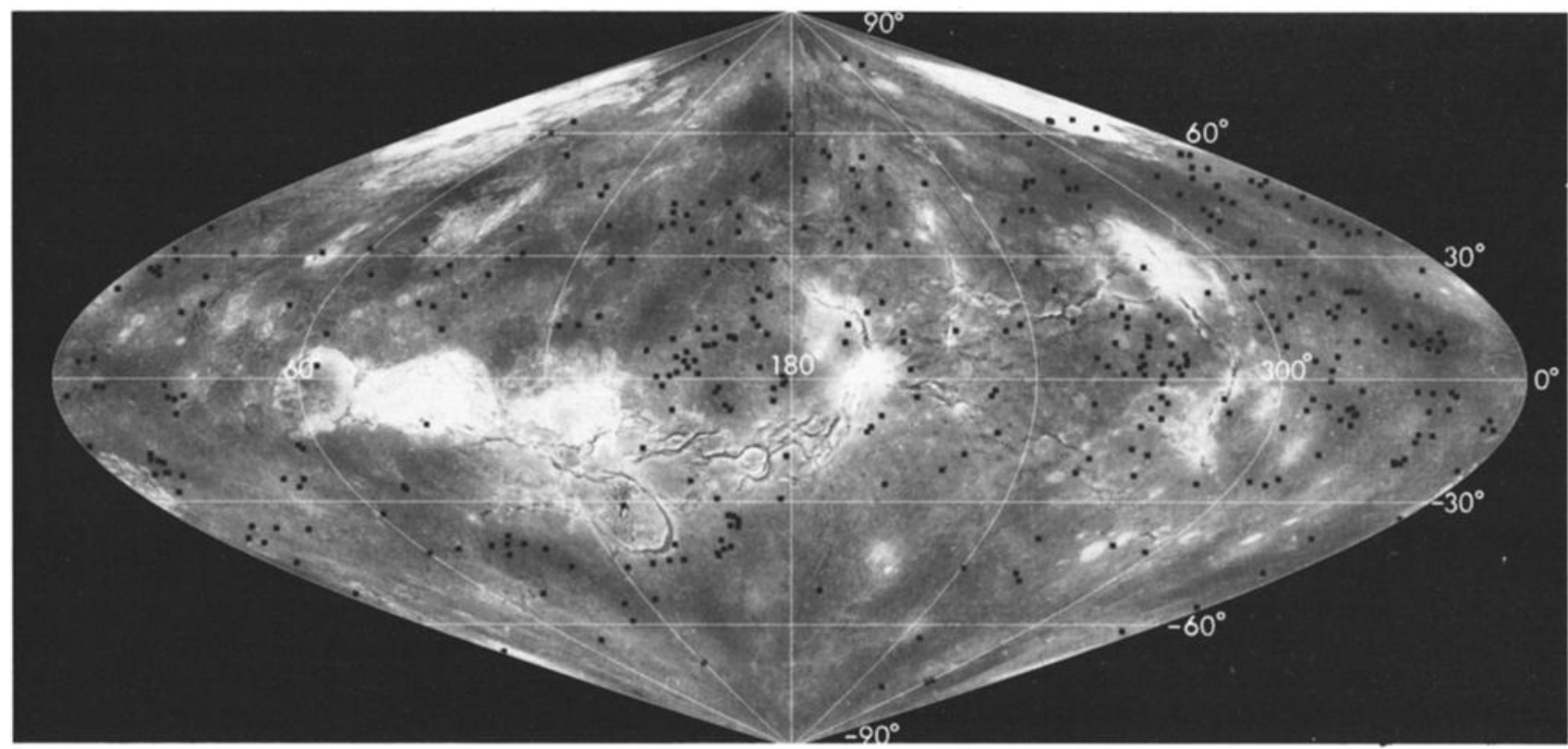

Figure 8. Sinusoidal equal-area altimetric map of Venus showing the distribution of the 401 recognizable splotches (all types).

markings, similar to splotches, surrounding an impact crater. These features should not be confused with dark margins, which have sharp boundaries that extend beyond the bright continuous ejecta deposits. They are probably an early, smooth part of the crater ejecta deposit. Like craterless splotches, most haloes are probably the result of atmospheric shock waves generated by the objects that formed the craters [Phillips et al., 1992; Schaber et al., 1992]. The haloes are normally 3-4 times larger than the associated crater, but some may be considerably larger. An acceptable database of haloed craters has not yet been compiled because of the difficulty in detecting such dark crater haloes within the extensive radar-dark plains (characterized by very weak radar backscatter) possibly associated with the parabolic deposits from large young craters. N. Izenberg (Wash-

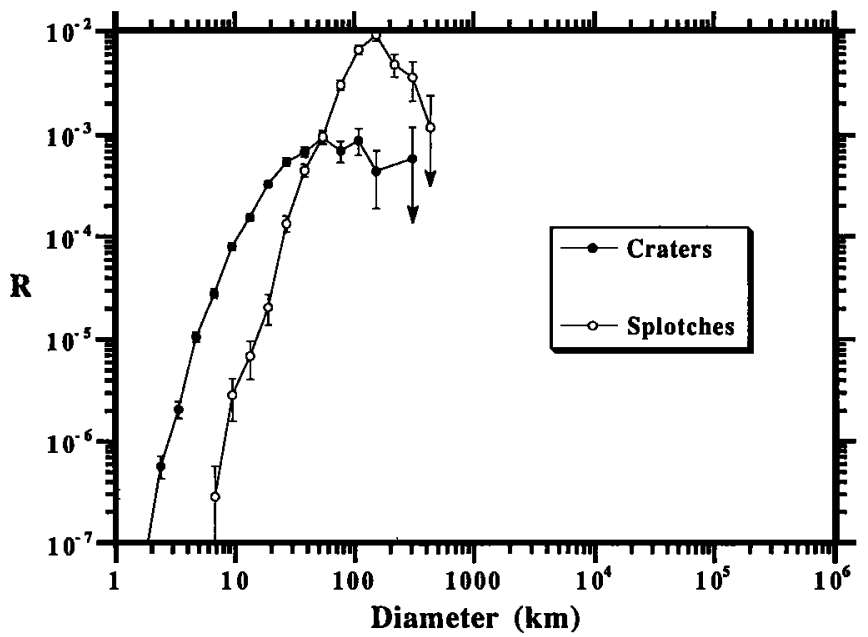

Figure 9. $R$ plot of the size/density distribution of Venus' impact craters compared to that of splotches. See text for definition of $R$ plot. ington University, St. Louis, Missouri) kindly provided us with a list of 62 craters that he considers to be candidate haloed craters that may be lava embayed. Two of the authors (R.G.S. and G.G.S.) have examined in detail all 62 craters that include 7 craters already classified by us as lava embayed. Of the remaining craters, we find that most are probably dark margin craters, and that only three are possibly embayed. However, these three do not show definitive evidence for embayment. Even if these three craters are embayed, it does not change the analyses discussed below.

Parabolic deposits. Dark parabolalike features (Figure 10) are associated with 58 craters on $92 \%$ of the surface [Campbell et al., 1992]. All but seven are oriented east-west with the apex to the east and the impact crater located just west of the apex. These features are interpreted to be fine-grained ejecta deposited downwind to the west by the zonal winds [Campbell et al., 1992; Vervack and Melosh, 1992]. The deposits range in width from about 160 to $1990 \mathrm{~km}$ and cover about $9 \%$ of the surface [Campbell et al., 1992]. In addition, nine extended features are more circular and may be related in origin to parabolic features. These features are similar to haloed craters, but they are larger: 7-20 crater radii compared with $3-4$ crater radii for haloes. Neither the parabolic features nor the circular extended features appear to have been embayed by lava [Campbell et al., 1992]. We have examined seven parabolic features that Izenberg considers to be embayed, but find no convincing evidence for embayment. Furthermore, nearly all the floors of craters associated with these features have high specific radar backscatter cross sections relative to their surroundings and tend to have low emissivities. These observations suggest that craters with parabolic features are the youngest craters on the planet.

Because parabolic features are probably fine-grained, wind-deposited ejecta, these deposits were probably once associated with all but the smallest impact craters on Venus. The older deposits have probably been eroded by eolian 


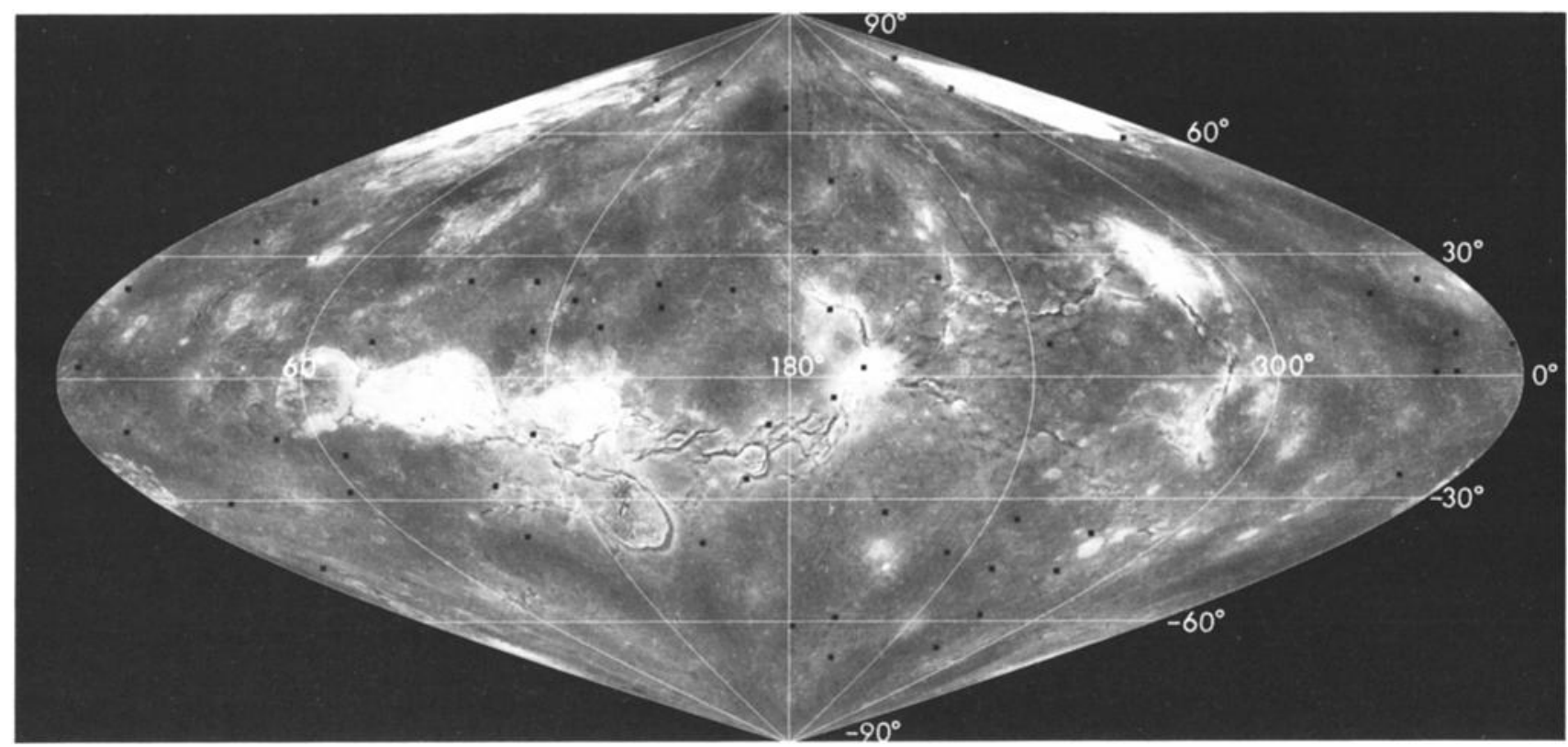

Figure 10. Sinusoidal equal-area altimetric map of Venus showing the 58 impact craters that have parabolic deposits, as listed in the work by Campbell et al. [1992].

processes. It is unlikely that eolian deposition has been a significant factor in covering these deposits because many craters are surrounded by shock-caused halos, but not by parabolic features. Eolian deposits a few centimeters thick would be expected to cover both types of features, unless the shock halos have a very rough surface expression compared to the parabolic deposits. The radar-dark nature of most halos suggests they are relatively smooth. The size/ density distribution of craters with parabolic features is virtually identical to that of the total crater population down to a diameter of about $7 \mathrm{~km}$ (Figure 11). However, no craters below this diameter have parabolic features, which suggests that these smaller craters did not loft their ejecta high enough to be carried downwind. If eolian erosion were the main cause of the absence of parabolic features for craters $<7 \mathrm{~km}$ in diameter, one would expect at least a few parabolic craters $<7 \mathrm{~km}$ among the younger craters, and a progressive

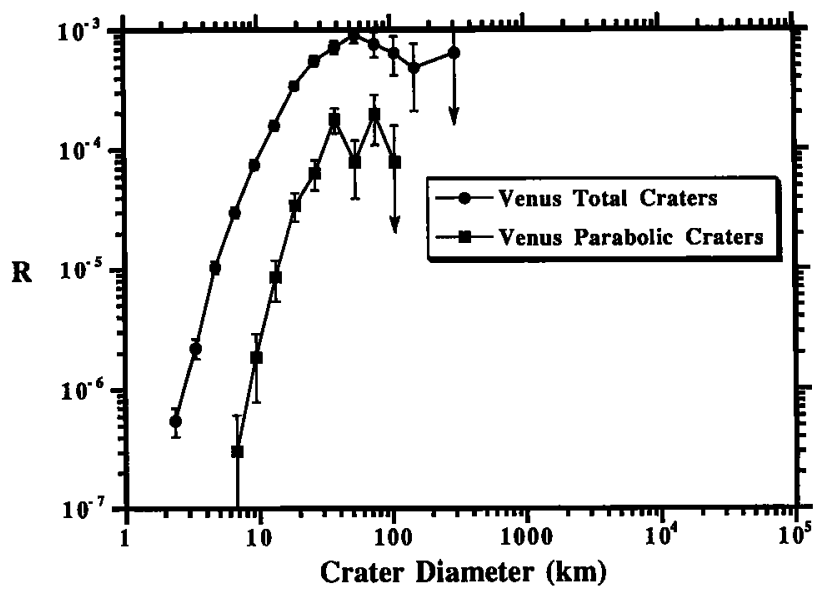

Figure 11. $R$ plot of the size/density distribution of all Venus impact craters compared to that of impact craters having parabolic features. loss of parabolic features with decreasing diameter, which is not observed (Figure 11).

The lifetime of parabolic features and the eolian erosion rate on Venus can be estimated from the average age of the surface and the present population of parabolic features [Strom, 1993]. Because at least 58 of the 932 craters have parabolic features and the average age of the surface is considered to be $300 \mathrm{~m} . \mathrm{y}$., then the average lifetime of parabolic features is about 19 m.y., but could be as short as $12 \mathrm{~m} . \mathrm{y}$. or as long as $44 \mathrm{~m} . \mathrm{y}$., in agreement with Basilevsky [1993]. This suggests that eolian erosion rates, particularly for unconsolidated material, are extremely low compared with those on the Earth and Mars. Campbell et al. [1992] estimated that the thickness of the parabolic deposits is several to tens of centimeters thick, possibly $0.16-3 \mathrm{~m}$. Table 2 lists the erosion rates for various deposit thicknesses and average lifetimes based on the estimated ages of the surface. They range from a maximum of $23 \mathrm{~cm} / \mathrm{m}$.y. to a minimum of $0.3 \mathrm{~cm} / \mathrm{m}$.y. If the larger circular features mentioned above are formed by the same process, then the erosion rates are even less. The reason for these low erosion rates is that the atmosphere is isothermal near the surface and therefore the wind velocities are small [Seiff, 1983]. Also, these erosion rates are presumably for unconsolidated or semiconsolidated material. They would be orders of magnitude smaller for

Table 2. Eolian Erosion Rates on Venus

\begin{tabular}{cccc}
\hline & \multicolumn{3}{c}{ Average Parabolic Lifetime, m.y. } \\
\cline { 2 - 4 } Deposit & 12.5 & 18.75 & 43.75 \\
\hline 15 & 1.2 & 0.8 & 0.3 \\
105 & 8.4 & 5.6 & 2.4 \\
195 & 15.6 & 10.4 & 4.5 \\
285 & 22.8 & 15.2 & 6.5 \\
\hline
\end{tabular}

Erosion rates are in units of $\mathrm{cm} / \mathrm{m} . \mathrm{y}$. 
consolidated material such as solid rock. These low erosion rates make it unlikely that eolian processes on Venus have had any significant effect in eroding the surface, which together with the lack of water and the relative youth of the surface, explains why the surface features are so well preserved. Paradoxically, of the three terrestrial planets with significant atmospheres (Earth, Mars, and Venus), the one with the densest atmosphere is the one least affected by erosion.

\section{Resurfacing Models}

A knowledge of the extent, timescale, and manner of resurfacing a planet is required to understand its geologic and thermal evolution. The uniquely well preserved cratering record on Venus places tight constraints on any proposed resurfacing model. Such a model must be able to explain, or at least not violate, the following seven constraints.

1. The areal distribution of the craters cannot be distinguished from a random distribution [Phillips et al., 1992; this paper].

2. The hypsometric (elevation area/crater density) distribution of the craters cannot be distinguished from a random distribution.

3. The random crater distribution is independent of size; small craters are as randomly distributed as large craters [Phillips et al., 1992; Schaber et al., 1992].

4. Fully $84 \%$ of the craters are in pristine condition.

5. Only $2.5 \%$ of impact-related features (crater deposits and craterless splotches) have been embayed by lava, and only $3.5 \%$ of the craters are highly fractured.

6. There is no definitive evidence that the parabolic features (covering about $9 \%$ of the surface) or the haloes surrounding craters have been embayed by lava.

7. The lava-embayed craters are concentrated in zones of recent volcanism, and the highly fractured craters are associated with major rift systems along the equatorial highlands.

Several resurfacing models have been proposed to explain the cratering record. These models can be divided into two broad categories: (1) equilibrium resurfacing, where resurfacing has been at a more-or-less constant, relatively high rate up to the present time, and (2) global resurfacing, where resurfacing has occurred episodically on a global scale. Another model suggests that endogenic processes have been steadily decreasing over Venus' history [Izenberg et al., 1993a]. One end-member model proposed equilibrium resurfacing, in which randomly distributed areas are resurfaced and craters destroyed at about the rate they form in order to maintain the estimated average surface age [Phillips et al., 1992]. Another end-member model examined by Phillips et al. [1992] was a global resurfacing event followed by complete termination of volcanic activity. Phillips et al. [1992] concluded that neither model (sensu stricto) is correct. Phillips [1993] and Herrick [1993], therefore adopted a modified equilibrium model, where only a limited number of areas (at least three) have been resurfaced. Schaber et al. [1992] proposed a global resurfacing model involving both tectonism and volcanism that ended about $300 \mathrm{~m}$.y. ago and obliterated the preexisting cratering record. Unlike the endmember global resurfacing model of Phillips et al. [1992], this event was followed by greatly reduced tectonism and volcanism. However, these processes did not cease entirely but have been concentrated at a very low level of activity in the equatorial region of abundant volcanic features and fracture belts. We examine these models below and show that the global resurfacing model proposed by Schaber et al. [1992] most likely accounts for the impact cratering record on Venus.

\section{Equilibrium Resurfacing}

Phillips et al. [1992] proposed an end-member equilibrium resurfacing model in which randomly distributed areas are resurfaced and craters destroyed at about the rate they form in order to maintain the estimated average surface age. This requires a more or less constant rate and spatially random distribution of volcanism up to the present time. If most volcanic features are due to mantle plumes [Head et al., 1992], then mantle thermal and physical properties must be able to generate randomly distributed plumes at a more or less constant rate. The model, as stated by Phillips $e t$ al. [1992], consists of two cases. In case 1 , small areas $\leq 150,000$ $\mathrm{km}^{2}(\leq 0.032 \%$ of the planet) are resurfaced at $\leq 150,000$ year intervals. In case 2 , large areas $\geq 4.5 \times 10^{7} \mathrm{~km}^{2}(\geq 9.8 \%$ of the planet) are resurfaced at $\geq 50 \mathrm{~m}$.y. intervals. The resurfacing interval depends on the resurfacing size and the average surface age, which these workers assumed to be 500 m.y. According to them, resurfacing areas between $\mathbf{0 . 0 3 2 \%}$ and $10 \%$ of Venus' surface produce a nonrandom crater distribution and therefore violate constraint 1 above, but resurfacing areas $\geq 10 \%$ produce a random distribution of craters that conforms to constraint 1 . It is not clear why the crater distribution should suddenly change from a nonrandom to a random distribution at $10 \%$ resurfacing, and we will show that indeed it does not until $100 \%$ (global) resurfacing is reached.

Schaber et al. [1992] have listed several objections to both cases of the equilibrium resurfacing model. We have performed new and more sophisticated Monte Carlo simulations that take into account the splotches and parabolic features. Here we will restate in more detail the previous objections and present new ones based on the computer simulations.

Equilibrium resurfacing requires that volcanic events be randomly distributed on a global scale in order for the resulting crater population to also maintain a random distribution. It also requires that the present distribution of volcanic landforms is part of equilibrium resurfacing. Although the individual size of constructional volcanic features and identifiable flood "basalt" deposits are about $\leq \mathbf{0 . 0 3 2 \%}$ of the planet (case 1), their distribution is far from random [Head et al., 1992]. In an inventory of 1660 volcanic landforms covering $90 \%$ of the planet, lowland areas are generally deficient in these features, although they may be the sites of massive flood basalts. There is a strong concentration of volcanic features ( $2-4$ times the global average) in the Beta-Atla-Themis region, which is about $20 \%$ of the surface [Head et al., 1992]. About half of the lava-embayed craters are concentrated in this region, indicating that the most recent activity occurred here. Our Monte Carlo simulations of global resurfacing (described below) indicate that about $2-3 \%(\sim 20-30)$ of the craters and crater-related features are destroyed. Because most of the embayed craters occur in the Beta-Atla-Themis region, it is likely that some of the destroyed craters will also be here and may contribute to the seeming below-average density of the larger craters, those 


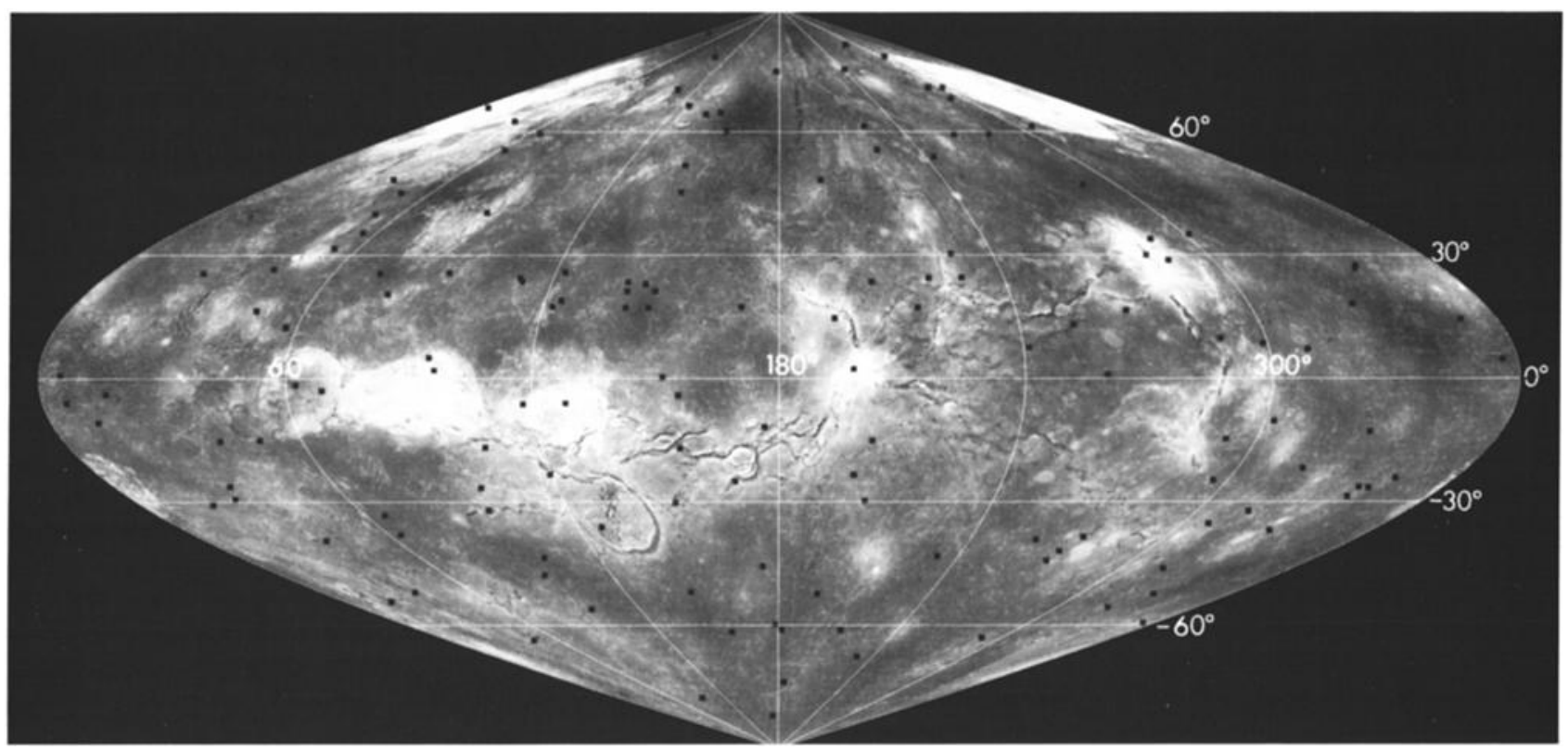

Figure 12. Sinusoidal equal-area altimetric map of Venus showing the distribution of craters with diameters $\geq 35 \mathrm{~km}$. The possible paucity of craters in the Beta-Atla-Themis region is the result of fewer craters in the 53-km size bin in this area, and shown in Figure 13. It may be a stochastic effect (see text for explanation).

$>35 \mathrm{~km}$ in diameter. However, it may also be a stochastic effect.

Figure 12 is a map of all craters $\geq 35 \mathrm{~km}$ diameter that shows an apparent deficit in the Beta-Atla-Themis region. Figure 13 shows the crater size/density distribution for the region with the densest concentration of volcanic features (which includes the Beta-Atla-Themis region with the heavi-

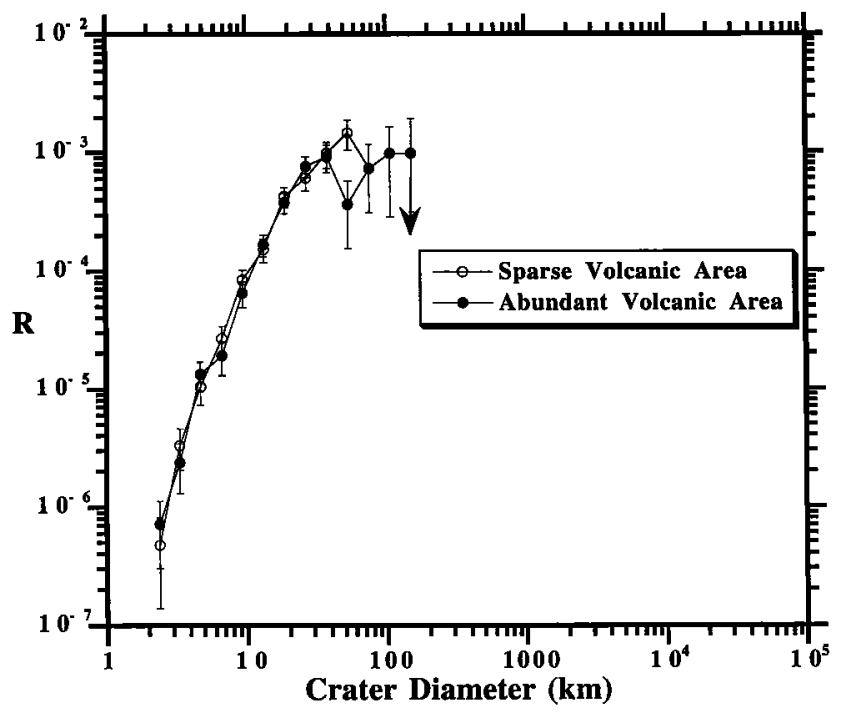

Figure 13. $R$ plot of the size/density distribution of craters in the Beta-Atla-Themis region which has the greatest concentration of lava-flooded craters on Venus, compared with the adjacent area, where flooded craters are sparse. Statistical tests of the data show that the size/density distributions for the two regions are not significantly different (see text for explanation). est concentration of flooded craters) compared with an adjacent region of equal area where the concentration of volcanic features is much less. It shows a close correspondence between the two curves except in one size bin $(53 \mathrm{~km})$ spanning diameters between 45 and $64 \mathrm{~km}$ ( 3 for the volcanic area versus 12 for the area with much fewer volcanic features). The paucity of craters of this size in the volcanic area is the cause of the apparent deficiency. However, there are three craters larger than $90-\mathrm{km}$ diameter in the volcanic area, but none in the area with much fewer volcanoes. We performed two types of statistical tests to determine if there was any statistically significant difference between the data sets; a t-test and chi-square tests. The t-test is for a normal distribution, and the Venus crater size/density distribution is similar to a lognormal distribution. In this test a value $>1.96$ indicates a difference between the two populations, and a value $\leq 1.96$ indicates no significant difference. The higher the value above 1.96, the greater the difference: the lower the value below 1.96, the greater the similarity. A value of zero indicates exact correspondence. The test gives a value of 0.50 , indicating no statistically significant difference between the two populations. The chi-square test of the entire data set, including the $53-\mathrm{km}$ size bin, gives a $P$ value of about 0.18 , indicating no evidence against the size/density distributions being the same. If the $53-\mathrm{km}$ size bin is excluded, the $P$ value is $\gg 0.25$, indicating a high probability that the two size/density distributions are statistically indistinguishable at all other diameters. If about nine large craters (45- to 64-km diameter) were completely destroyed by volcanic processes, it is likely that this volcanism would also destroy an even greater fraction of small craters. This is clearly not observed, as demonstrated by the statistical tests. Therefore any loss of craters by volcanic flooding in the region of abundant volcanoes is very small compared with the adjacent region and not statistically significant. The 


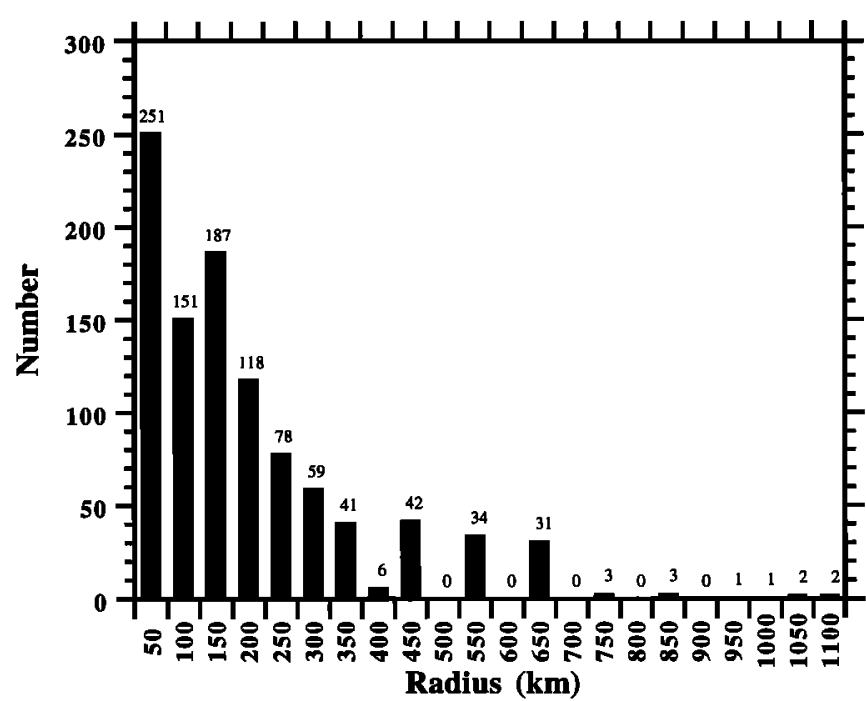

Figure 14. The binned size distribution of volcanoes used in the Monte Carlo simulations [after Head et al., 1992].

apparent deficiency could simply be the result of a stochastic variation in the random crater population (suggested by the high $P$ value for the complete data set), although the destruction of a few large craters cannot be ruled out.

Monte Carlo simulations used to test the equilibrium resurfacing model were for the entire planet, including the $\sim 20 \%$ of the surface covered by highlands and tesserae. If the highlands and tesserae were excluded from the simulations, there would be no craters in these areas, contrary to observation. Because about $80 \%$ of the planet's surface displays volcanic features, these simulations are representative of the postulated equilibrium volcanic resurfacing. The simulations included the observed 932 impact craters, the 401 impact-produced splotches, and the parabolic craterrelated features. Crater ejecta blankets were also included in the simulations. Measurements of ejecta blanket width indicate they are about one crater radius, exclusive of the large ejecta outflows. For the simulations the crater diameters were taken to be twice that observed to include the ejecta blankets. This is a conservative value because it does not include (1) the large ejecta outflows associated with $43 \%$ of the craters, which can extend more than four crater diameters from the rim [Chadwick and Schaber, 1993], and (2) the halo diameters, which have not yet been measured. Because the parabolic features are not circular, we used the equivalent diameters of their areas as listed by Campbell et al. [1992]. Because these features are probably associated with the youngest craters, they were put down last in the simulations.

The Monte Carlo simulations randomly selected the location and size of impact craters and resurfacing events at time intervals that would produce the average age of the surface with approximately the observed number of craters and splotches. Each crater and splotch was checked to determine if its distance from the event is such that it should be untouched, partially embayed, or obliterated. Crater and volcanic event emplacement were repeated until the simulation time reached the present.

Seven types of simulation were run: (1) equal-sized resurfacing areas comprising $0.001 \%$ of the planet at 5000 -year
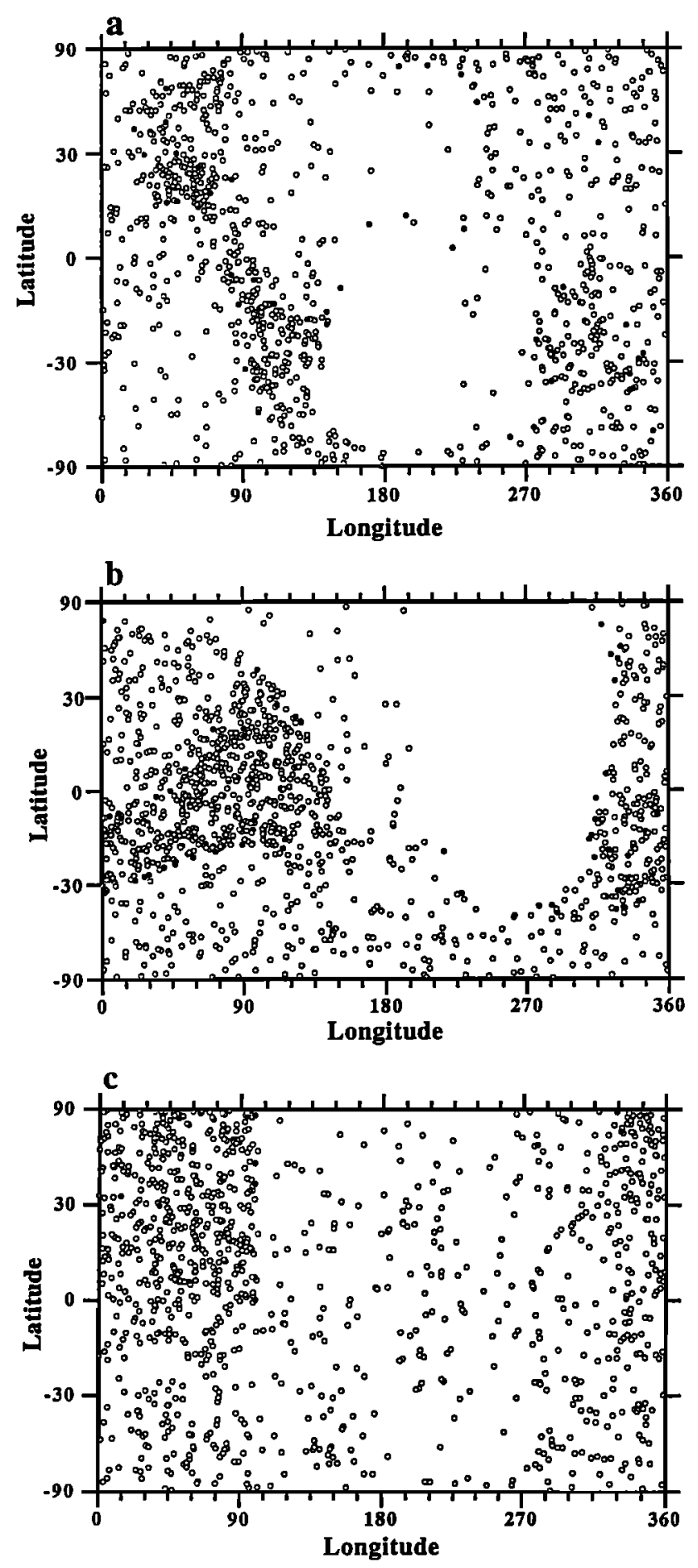

Figure 15. Results of Monte Carlo simulations of equilibrium resurfacing based on resurfacing areas of (a) $10 \%$, (b) $25 \%$, and (c) $50 \%$ of Venus. The distributions are conspicuously nonrandom. Open circles are pristine craters, and solid circles are embayed craters. The map projection in this figure and those in Figures 16-18 are simple cylindrical projections using the sine of the latitude to remove highlatitude distortions in crater distributions.

intervals, (2) equal-sized resurfacing areas comprising $0.01 \%$ of the planet at 50,000-year intervals, (3) equal-sized resurfacing areas comprising $0.03 \%$ of the planet at 150,000 -year intervals, (4) the observed size distribution of volcanic 
features (Figure 14) at 50,000-year intervals, (5) equal-sized resurfacing areas comprising $10 \%$ of the planet at $50-\mathrm{m} . \mathrm{y}$. intervals, (6) equal-sized resurfacing areas comprising $25 \%$ of the planet at 125-m.y. intervals, and (7) resurfacing areas comprising $50 \%$ of the planet at $250-\mathrm{m}$.y. intervals. The time interval of the impact and volcanic events was for an average surface age of $500 \mathrm{~m} . \mathrm{y}$. Although the actual surface age may be closer to $300 \mathrm{~m} . y$., the results of the simulations would not change, only the relative time interval between events.

Figure 15 shows maps (cylindrical projections) of the simulations for resurfacing areas of $10 \%, 25 \%$, and $50 \%$. In the simulation for $50 \%$ resurfacing (Figure $15 \mathrm{c}$ ), the surface is shown just before the next resurfacing event, so it has accumulated a modest amount of craters. In all three simulations the resulting crater distributions are clearly nonrandom. Therefore case 2 of the equilibrium resurfacing model violates constraint 1 that the crater population has a spatially random distribution. The simulation of $25 \%$ area resurfacing is similar to the resurfacing model of Phillips [1993] and Herrick [1993] that proposes at least three large resurfacing areas on Venus. However, this model violates both constraints 1 and 2 of a spatially and hypsometrically random crater distribution.

The small-area equilibrium resurfacing simulations (case 1) kept track of the following results: (1) the minimum (status 1) and maximum (status 2) number of embayed craters, (2) the number of pristine craters and splotches (status 0), (3) the number of craters and splotches destroyed (status 3), (4) the simulation age of each impact, and (5) the percentage of the planet resurfaced. The simulations were run for a computer time of $3.5 \mathrm{~b} . \mathrm{y}$. The crater classification criteria are as follows. If the distance between a crater and a volcanic event is greater than the sum of the radii of the crater and event, then the crater remains pristine (status 0 ). If the entire crater falls within the radius of the event, the crater is considered destroyed (status 3). When a crater falls between status 0 and status 3 , the fraction of the area covered by the volcanic event is recorded, and if this happens multiple times, these fractions are added together. If the central point is never covered, or if the sum of the fractional areas never exceeds 1 , then the crater is considered embayed (status 1 ). On the other hand, if this sum exceeds 1 and the central point of the crater is covered by a volcanic event, then the crater is certainly embayed but could also be destroyed (status 2). Thus the number of status 1 craters is the minimum number of embayed craters, and the number of status 1 plus status 2 craters is the maximum number of embayed craters. In reality, the number of embayed craters is probably somewhere between these numbers. After experimentation with a grid of points, these criteria proved to be a relatively good measure of crater condition.

The most realistic small-area equilibrium resurfacing model is one that uses the observed volcano size distribution (Figure 14) rather than geologically unrealistic equal areas. In this simulation the interval between events is 50,000 years, which produces about 1300 impact features that are observed (about 900 craters and 400 splotches). In this simulation the entire planet was resurfaced seven times, and over 6000 craters were destroyed. Figure 16 shows the results of the simulation compared with the observed crater distribution, which here appears to be random, but the minimum number of embayed craters is about 18 times the number actually observed (48\% rather than $2.5 \%$ ). Our
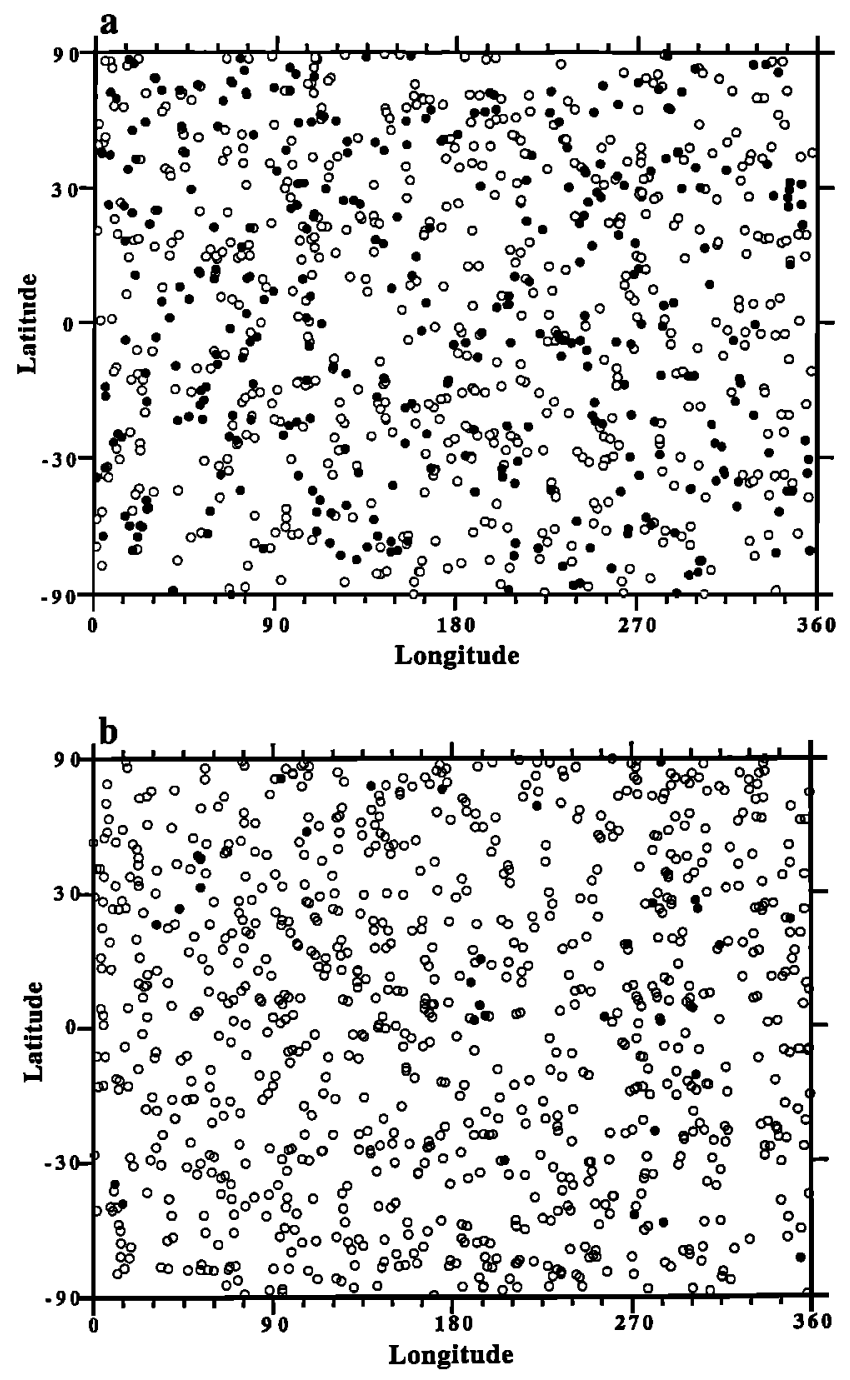

Figure 16. Results of Monte Carlo simulation of the equilibrium resurfacing model using (a) the observed volcano size distribution compared to (b) the distribution of embayed craters actually observed. Open circles, pristine craters; solid circles, embayed craters or crater-related features. The percentage of embayed craters and related features produced by this simulation is a minimum of $48 \%$ compared to the $2.5 \%$ actually observed.

simulations using equal resurfacing areas produced even more flooded craters and resulted in a crater size/density distribution that was different from that observed. For $0.03 \%$ equal-sized resurfacing areas (considered to be the best case by Phillips et al. [1992]) the minimum percentage of embayed craters is $43 \%$; for $0.01 \%$ it is $56 \%$; and for smaller areas it is more than $70 \%$ (Figure 17). Thus, as the resurfacing area decreases, the percentage of embayed craters increases. Furthermore, at the end of the equal-area simulations, the crater size/frequency distribution is very different from that observed. The repeated obliteration of craters resulted in the loss of smaller craters, so that the size distribution steepened appreciably at diameters $>35$ compared with that of the input population. In order for the simulations to produce the observed size distribution at the end of a run, it was necessary to input a size distribution with a differential -4 slope at diameters greater than $35 \mathrm{~km}$. Such 

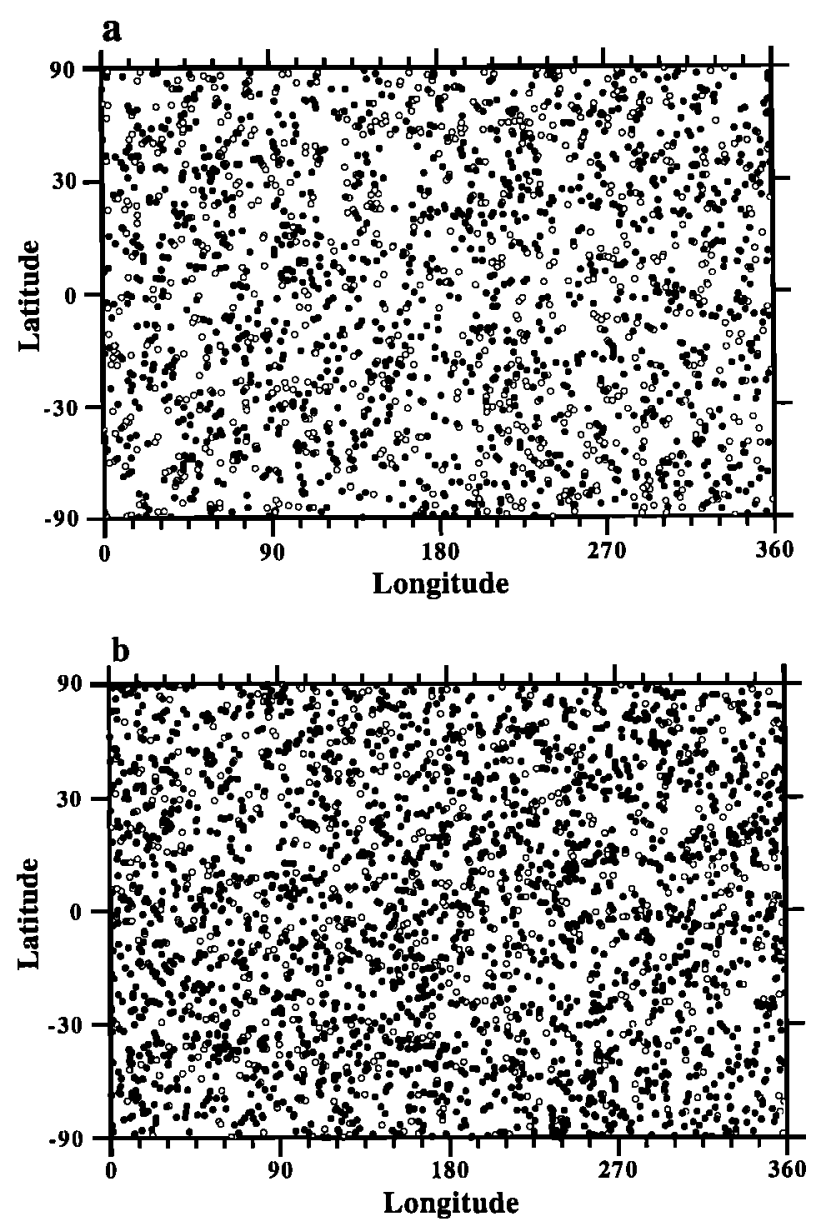

Figure 17. Results of Monte Carlo simulations of the equilibrium resurfacing model for equal areas comprising (a) $0.03 \%$ of the surface and (b) $0.01 \%$ of the surface. Open circles, pristine craters; solid circles, embayed craters or crater-related features. The minimum percentages of embayed craters are $43 \%$ and $56 \%$, respectively. Compare with observed embayed craters in Figure 16b.

a production size/frequency distribution is not observed anywhere in the inner Solar System [Strom et al., 1992]. None of these models comes close to reproducing the observed percentage of embayed impact features.

Thus the volcanic equilibrium resurfacing model is not supported because (1) it produces many more flooded craters than observed (case 1) or it produces a nonrandom crater population (case 2); (2) the observed volcano population is not randomly distributed as required by the model; (3) the embayed craters are not randomly distributed as they should be for random volcanism; and (4) the number of observed volcanoes is only a third that required by the model [Schaber et al., 1992; Head et al., 1992].

Resurfacing models involving crater destruction by tectonic processes [Solomon, 1993a, b] are also unlikely to explain the characteristics of the global impact crater population. For uniformly distributed stresses there should be a more or less equal number of pristine, lightly fractured and heavily fractured craters, and this is clearly not the case (see Table 1). Also the fractured craters should have a random distribution, which is also not the case (see Figures $7 \mathrm{~b}$ and 7c). Even if the stresses were episodic, equilibrium resurfacing requires a random distribution of stresses and, consequently, a random distribution of fractured craters. Furthermore, the observed tectonism is not randomly distributed over the surface as required by equilibrium resurfacing, and about $80 \%$ of the surface is covered by volcanic features [Head et al., 1992] with only $2.5 \%$ of craters and crater-related features being embayed by lava. Neither of these facts can be reconciled with tectonic equilibrium resurfacing acting alone or in concert with volcanic equilibrium resurfacing.

Izenberg et al. [1993a, b] have suggested that the cratering record can be explained by endogenic processes steadily decreasing over time. This model is based on various crater radar characteristics (primarily extended ejecta deposits) that suggest systematic changes in these characteristics with time. However, these radar changes are mostly for superficial deposits, e.g., thin, fine-grained material. They are not observed in major crater morphology, such as rims and continuous ejecta that do not vary as a function of preservation state. These changes are probably the result of atmospheric effects on crater deposits that may indicate the relative age of a crater and/or its elevation. The correlation of decreasing extended ejecta deposits with fractured and embayed craters may indicate a decrease in internal activity following the global resurfacing event, but it is unlikely that it represents a gradual decline in internal activity over billions of years. Such a decline in internal activity would be expected to result in a more or less equal number of pristine, fractured, and embayed craters, which is clearly not observed (Table 1).

\section{Global Resurfacing}

The global resurfacing model proposes that a global resurfacing event involving both tectonism and volcanism occurred about $300 \mathrm{~m} . \mathrm{y}$. ago and obliterated the preexisting cratering record. There is no way of determining whether global resurfacing was continuous throughout the history of Venus and ceased about $300 \mathrm{~m}$.y. ago, or whether there were episodic global resurfacing events up to this time. However, several thermal history models (discussed later) suggest that earlier periodic resurfacing events may have occurred. Also, continuous global resurfacing throughout the past 4 b.y. would have resulted in such a high rate of heat loss that the planet would almost certainly have ceased to be active much sooner than $300 \mathrm{~m}$.y. ago. Therefore we consider the latest global resurfacing as a discrete "event" in the history of Venus. Its duration is unknown, but it must have ended suddenly relative to the crater production rate (discussed below). Otherwise, there would be significant variations in the crater density and size/density distribution. This event was followed by greatly reduced tectonism and volcanism on a global scale; however, these processes clearly did not cease entirely [Schaber et al., 1992]. The observed crater population has accumulated up to the present time, and the present stratigraphy of the volcanic plains and highland surfaces is largely, but not entirely, the result of the latest resurfacing event. Modification of those surfaces over the past $300 \mathrm{~m}$.y. or so has been dominantly the result of simple fracturing (with limited extension) and regional volcanism at such a low level that the cratering record was left virtually intact.

The global resurfacing model simply and easily accounts 
for all constraints on resurfacing imposed by the cratering record. It is consistent with (1) the spatially random crater distribution and its diameter independence, (2) the random hypsometric crater distribution, (3) the very low abundance of embayed craters and crater-related features, and (4) the low abundance of fractured craters. Further, the model is consistent with the concentration of embayed and highly fractured craters at zones of recent volcanism and tectonism. Price and Suppe [1993] also find the crater distribution is inconsistent with equilibrium resurfacing, and instead reflects a production population modified by limited tectonism and volcanism.

The amount of volcanic resurfacing since the global event can be estimated from the Monte Carlo simulations described above. These simulations are similar to the one for equilibrium resurfacing that used the observed volcanic and impact-related size distributions. In this case the starting time ranges from 300 to $500 \mathrm{~m} . \mathrm{y}$. ago, and the interval between resurfacing events is such that at the present time only the observed $2.5 \%$ of impact-related features are embayed. These simulations required resurfacing intervals of 750,000 years and $1 \mathrm{~m} . \mathrm{y}$. About 20 simulations were run, in which both the crater-related features and the volcanic events were laid down randomly over the entire surface, with the parabolic features being laid down last. Therefore, contrary to observation, volcanic features and embayed craters appear to have a more or less random distribution. Figure 18 shows a typical simulation. This particular simulation (Figure 18a) shows an apparent concentration of embayed craters between longitudes 210 and 335, and latitudes -5 and -55 that is solely the result of stochastic variations in a random crater and volcano distribution of low density. This stochastic concentration is not unlike the concentration observed (Figure 16b) and illustrates the need for caution in interpreting what appear to be "clusters" and "holes" in a random distribution. In reality, the observed concentration of embayed craters on Venus coincides with the concentration of volcanic features mapped by $\mathrm{Head}$ et al. [1992] in the Beta-Atla-Themis region. This correlation suggests that the most recent volcanism is concentrated in this region and may still be active today. It does not, however, preclude the possibility that other areas of Venus are currently active (see section below on postglobal resurfacing activity).

In the simulation shown in Figure 18 the observed number of crater-related features were laid down, of which 21 were destroyed and 39 embayed. These numbers, however, varied depending on stochastic effects and the starting time. The number of volcanic events required to cause about $2.5 \%$ embayed craters and related features ranged from 400 to 600 (Figure 18b), and the percentage of the planet resurfaced ranged from $4 \%$ to $6 \%$. In reality, each of the $400-600$ events would probably consist of more than one eruption, so that the cumulative number of eruptions could have been much more. One or two eruptions at one site might result in a lava thickness of about $100 \mathrm{~m}$, but multiple eruptions at one site could build an edifice about $1 \mathrm{~km}$ thick or more (there are not $400-600$ volcanoes $1 \mathrm{~km}$ high on Venus). If we consider all the deposits to be $100 \mathrm{~m}$ thick or all of them to be $1 \mathrm{~km}$ thick, then this should span upper and lower limits of deposit thicknesses. Thus the probable minimum and maximum lava production rate on Venus is $0.01-0.15 \mathrm{~km}^{3} / \mathrm{yr}$ since the global event. This is about 10 times less to slightly more than
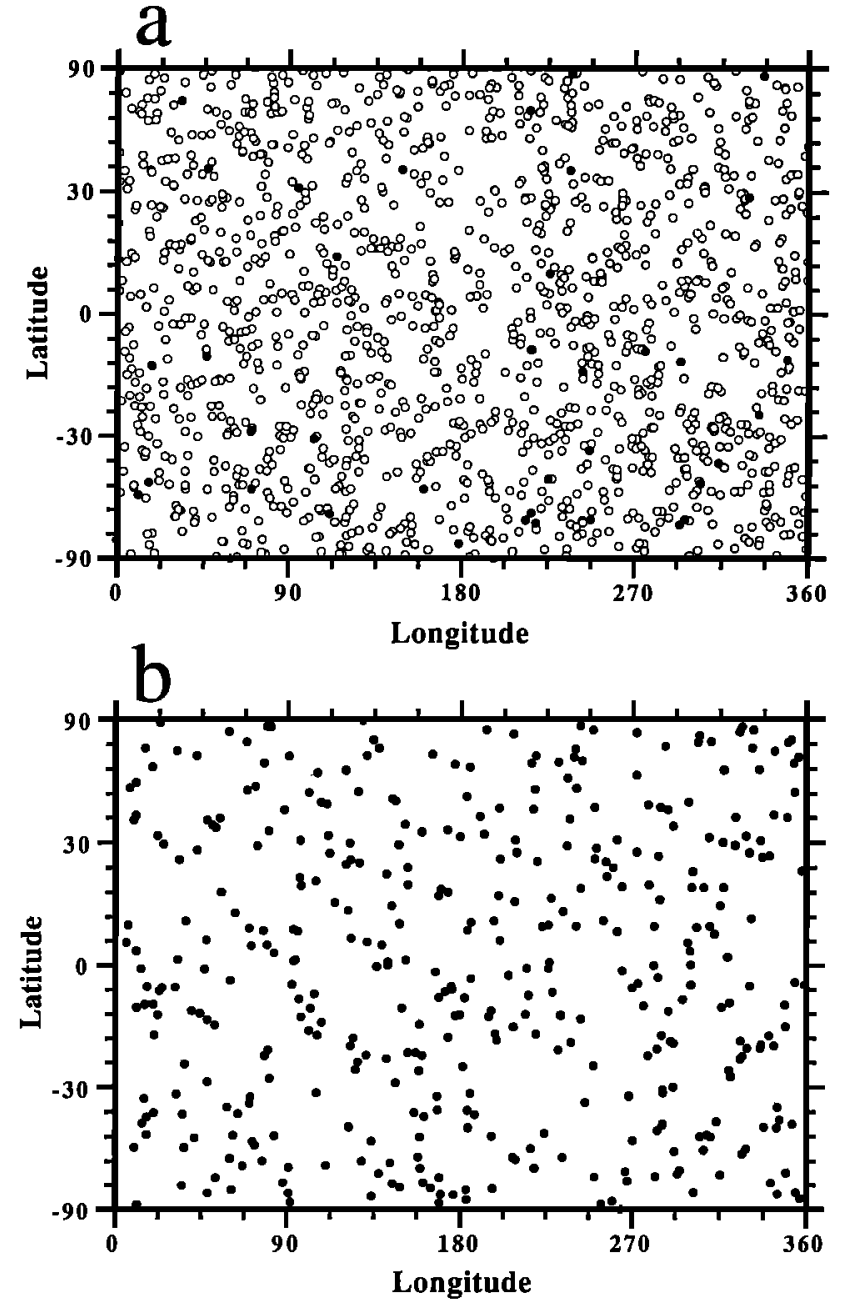

Figure 18. Results of one Monte Carlo simulation of resurfacing after the global event, showing (a) the pristine craters (open circles) and embayed craters (solid circles) and (b) the volcanic features. In this simulation, about $5 \%$ of the planet is resurfaced to produce about $3 \%$ embayed craters. See text for explanation.

the lava production rate $\left(0.11 \mathrm{~km}^{3} / \mathrm{yr}\right)$ of Kilauea alone, one of the most active volcanoes on Earth [Holcomb, 1987]. From estimates of the volumes of mapped volcanic features on Venus, Head et al. [1992] estimated an eruption rate of $<0.1 \mathrm{~km}^{3} / \mathrm{yr}$ for an average surface age of $500 \mathrm{~m}$. $\mathrm{y}$. Thus the estimated eruption rates since the global resurfacing event are less than estimated current rates of intraplate volcanism on Earth $\left(0.33-0.5 \mathrm{~km}^{3} / \mathrm{yr}\right)$, and orders of magnitude less than the Earth's magmatic output (intrusive and extrusive) of $26-34 \mathrm{~km}^{3} / \mathrm{yr}$ [Crisp, 1984].

Bullock et al. [1993] used a three-dimensional Monte Carlo resurfacing simulation of Venus to simulate equilibrium resurfacing and to derive the resurfacing rate. They found that equilibrium resurfacing produced more lava-embayed craters (about $15 \%$ ) than observed, and that a global resurfacing event is more consistent with the cratering record. They also derived a lava production rate of $0.37 \mathrm{~km}^{3} / \mathrm{yr}$. We concur with their general conclusion concerning the likelihood of a global resurfacing event, but we strongly disagree with their percentage of embayed craters for equilibrium 
resurfacing and with their lava production rate. The percentage of embayed craters for equilibrium resurfacing is far too small, and the lava production rate is far too large. We agree that three-dimensional (3D) Monte Carlo simulations more accurately portray volcanic resurfacing than our twodimensional (2D) simulations because they take into account surface elevations, crater depth and rim height, and lava thickness. However, their 3D simulations failed to account for ejecta blankets and crater-related features such as craterless splotches, haloes, and parabolic deposits, all of which are part of the impact cratering record, and none of which are embayed by lava. Ejecta blankets on Venus extend about 1 crater radius. Therefore the area covered by the ejecta deposit is 4 times that of the crater. If this alone was taken into account, the percentage of embayed craters would about double and the lava production rate would decrease by about a factor of 2 . Furthermore, in their simulations they used a single-slope size distribution at diameters $\geq 16 \mathrm{~km}$ (presumably differential -3 that represents diameters $>32$ $\mathrm{km})$. Therefore craters below $16-\mathrm{km}$ diameter were not included in their simulation. There is a paucity of craters relative to -3 slope below $32-\mathrm{km}$ diameter due to atmospheric screening of projectiles. Although this would overestimate the number of craters between $16-$ and $32-\mathrm{km}$ diameter, it would not make up for the 500 craters $<16-\mathrm{km}$ diameter. The difference is about 300 craters. When the 400 craterless splotches, the $9 \%$ of the surface covered by parabolic features, the ejecta blankets, and the 300 craters not included in their simulations are taken into account, the number of embayed craters for equilibrium resurfacing will surely increase significantly, and the resurfacing rate will surely decrease correspondingly. We believe that when the observed cratering record is used in their simulations, the results will be in much better accord with our Monte Carlo simulations.

The global resurfacing event probably lasted at least tens of millions of years. The mid-Cretaceous "superplume" on Earth lasted 40 m.y. [Larson, 1991a], and its effects were much less than the global event on Venus. On Venus the global resurfacing event may have lasted much longer. That event was certainly not just one synchronous resurfacing episode that occurred in an instant of geologic time. Stratigraphic relations show clear evidence for different ages of various terrains. For instance, many fractured highland areas have clearly been embayed by surrounding lava plains (Figure 19). Therefore at least some highland areas are older than their surrounding plains. Other highland areas may be younger than some plains, and some plains and volcanic constructs are surely older than others. These age variations would be expected to result from a global event lasting tens of millions of years or more. The key question is not whether there are age differences between terrains (there clearly are), but what is the absolute time interval between formation of the terrains that result from the global event. Our view is that the intervals are relatively short on a geologic timescale, within the duration of the global event.

This event has often been referred to as "catastrophic" resurfacing, which may be true in the context of a geologic timescale of $4.5 \mathrm{~b}$.y. However, the term is certainly inappropriate compared with truly catastrophic events such as impact cratering, which can take place in a matter of seconds, or the formation of outflow channels on Mars, which may have required only hours or weeks. The entire span of human history could have taken place during such a global resurfacing event without humans ever knowing it was occurring.

However, like the terrestrial mid-Cretaceous superplume, the termination of the global event on Venus may have been abrupt. The very small number of fractured and lavaembayed craters, most of which are concentrated in zones of recent tectonism and volcanism, suggests that it ended in a short time compared to the cratering rate. An estimate of the rapidity with which the global resurfacing event ended can be determined by Monte Carlo simulations using the estimated cratering rate (see section above on average surface age) and an initially high resurfacing rate that declines with time over the period since the global resurfacing event. In these simulations the interval between resurfacing events was increased as the simulation progressed. For a given initial resurfacing interval the rate of this increase was determined by varying it in multiple runs. The rate of increase that results in the observed percentage of embayed craters and crater-related features (2.5\%) sets the upper time limit for terminating the global resurfacing event. For a wide range of initial resurfacing intervals, the Monte Carlo simulations suggest that the global resurfacing event ended within a time interval no greater than $10 \mathrm{~m}$.y. It probably ended within a shorter period of time, but a more accurate estimate cannot be determined because of the uncertainties in the crater production rate.

The global resurfacing event involved both tectonism and widespread volcanism that probably operated in concert. The various terrains have complex relative ages: (1) plains have a variety of stratigraphically different ages, (2) fracture belts transect plains and highlands and, in turn, are locally embayed by plains, (3) in some areas, e.g., Ishtar Terra, the folded margins of highlands postdate the adjacent plains, and (4) coronae show a variety of relative ages.

In general, most of the plains surrounding tesserae appear to embay these units and are therefore younger (Figure 19). This suggests that intense crustal disruption generally, but not wholly, preceded widespread plains volcanism. Tesserae are the most highly disrupted terrain on Venus and may be the only terrain that has survived the last global resurfacing event, although it has been severely disrupted by it. It is the only terrain that has circular features that may be highly disrupted impact craters that survived the global resurfacing event. Detailed geologic mapping of this terrain will help place it within the context of the global resurfacing model and may show multiple episodes of major deformation events that coincide with earlier global resurfacing events [Chadwick and Schaber, 1994].

The subtle stratigraphic age differences that occur on most of the Venusian plains likely date from late stages of the global resurfacing event [Komatsu et al., 1993]. Komatsu et al. [1993] have also suggested that the global resurfacing event may be responsible for the formation of the remarkable canali-like channels on the planet. Unfortunately, these differences in age cannot be determined by crater statistics because of the low overall density and statistically random spatial and hypsometric distribution of craters. Refinement of the relative chronology of events within this global resurfacing episode and the limited activity that followed will require detailed geologic mapping using established stratigraphic methods. 


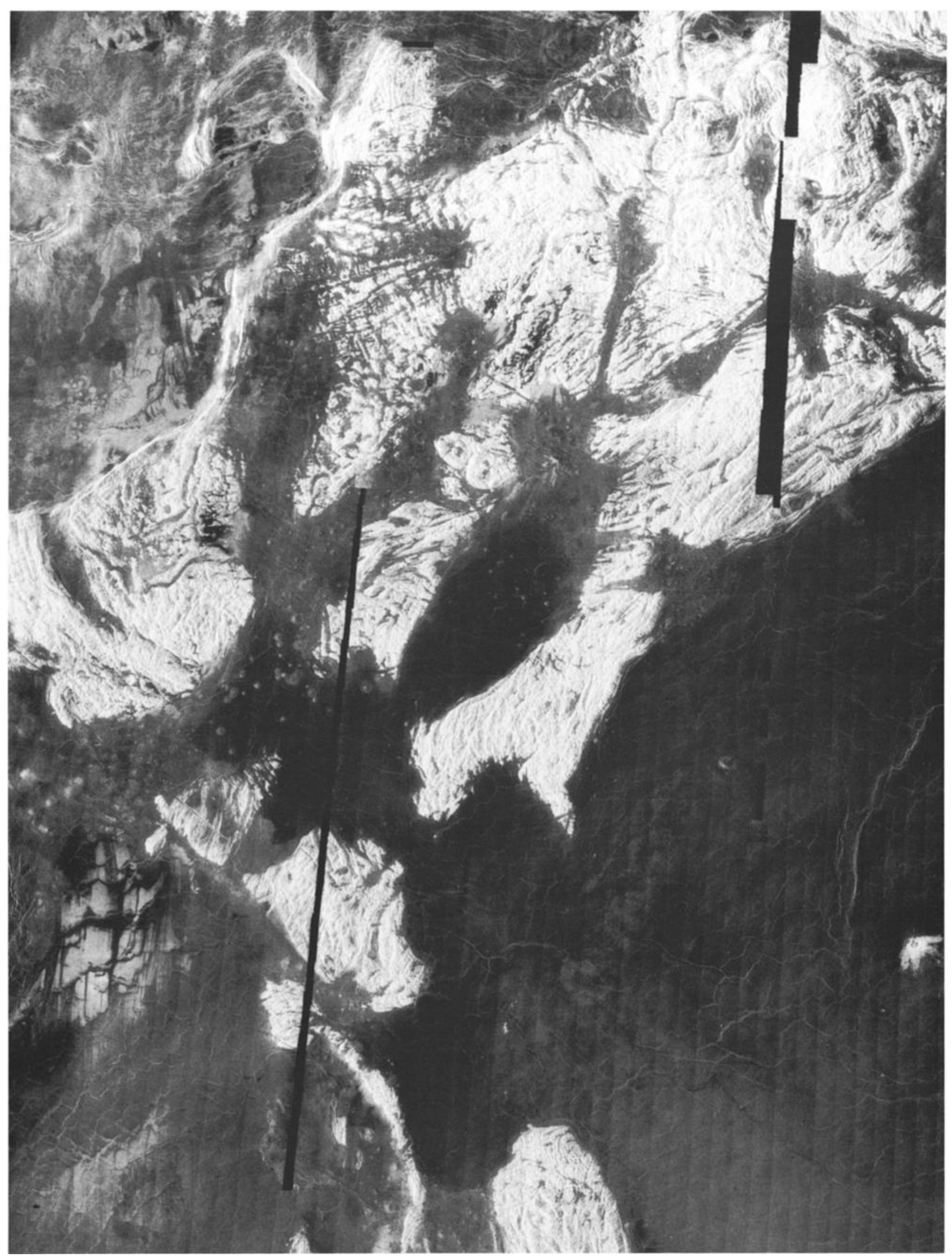

Figure 19. The Ananke Tessera area of Venus showing this elevated terrain is embayed by the surrounding plains. Size of area is about $970 \times 825 \mathrm{~km}$ (Magellan image C1-45N138). 


\section{Atmospheric Implications of Global Resurfacing}

Whether there were multiple global resurfacing events throughout the history of Venus cannot be clearly discerned from the present geologic record. The present surface is largely a record of the last event and of the comparatively minor activity that followed. Evidence for past events has been largely destroyed by the latest event, although the tesserae may provide some evidence for past events. However, thermal history models (discussed below) suggest that global resurfacing events would have occurred, or are occurring, episodically (see section below on global resurfacing mechanisms). If this is correct, then earlier global events probably occurred and may have contributed significantly to the atmospheric $\mathrm{CO}_{2}$ abundance. Although the nature of the global resurfacing events is uncertain, they may have been analogous, in part, to large-scale versions of the terrestrial "superplume" proposed to have caused major plateau basalt effusion lasting about $40 \mathrm{~m} . \mathrm{y}$. in the mid-Cretaceous, some $125 \mathrm{~m} . \mathrm{y}$. ago [Larson, 1991a, b]. The terrestrial superplume (discussed below) may have added 3.7-14.7 times the preindustrial $\mathrm{CO}_{2}$ content (285 ppm) to the atmosphere and caused a greenhouse warming of $2.8^{\circ}-7.7^{\circ} \mathrm{C}$ above the present global average [Caldeira and Rampino, 1991]. We do not know the volume of material involved on Venus, but a 10-km-thick layer of basalt, for example, could produce about 13 bars of $\mathrm{CO}_{2}$ if it supplied a terrestrial basalt $\mathrm{CO}_{2}$ weight fraction of 0.0052 [Caldeira and Rampino, 1991]. Carbonatites, which contain about $40 \mathrm{wt} \% \mathrm{CO}_{2}$, are candidate materials in which the long, sinuous channels on Venus may have formed [Baker et al., 1992]. The amount of $\mathrm{CO}_{2}$ exsolved from carbonatites depends on the pressure and temperature during the time of eruption. If carbonatites constitute a relatively small fraction of the resurfacing material, then a significantly smaller volume of volcanics is needed for comparable amounts of $\mathrm{CO}_{2}$. For example, a global layer of carbonatite $500 \mathrm{~m}$ thick could supply about 19 bars if only half of the $\mathrm{CO}_{2}$ content was exsolved. Thus global resurfacing events on Venus may have been responsible for a significant part of the present 90 -bar $\mathrm{CO}_{2}$ atmosphere.

The high abundance ratio of deuterium to hydrogen in the atmosphere of Venus (120 times that on Earth) has been interpreted to be consistent with Rayleigh fractionation after (1) massive outgassing from global resurfacing of the planet in the past $0.5-1 \mathrm{~b} . \mathrm{y}$. or (2) continuous outgassing from a highly fractionated mantle source [Grinspoon, 1993]. Considering the cratering record discussed above, we believe it is more likely that the high $D / H$ ratio is due to global resurfacing.

\section{Postglobal Resurfacing Activity \\ Recent Activity}

On Venus the most recent activity postdating the global event has occurred along broad fracture belts that crisscross the middle latitudes of the planet, which were first described from Pioneer Venus altimetry data [Masursky et al., 1980, Figure 15; McGill et al., 1981; Schaber, 1982]. Three broad tectonic "disruption zones" (Figure 1) were named the Aphrodite-Beta, Themis-Atla, and Phoebe-Beta zones, and they were attributed at that time to limited horizontal extension [Schaber, 1982]. The Magellan data support this inter- pretation and show the disruption zones to be composed of complex, anastamosing belts of closely spaced fractures, fracture troughs, grabens, coronae, and volcanic eruption centers. Where the three disruption zones broadly intersect in the vicinity of Maat and Ozza Montes in Atla Regio and Theia Mons in northern Beta Regio, there may be evidence of ongoing shield volcanism. This was also suggested earlier from analysis of Pioneer Venus data in conjunction with the coincidence of elevated terrains and strong positive gravity anomalies at these tectonic intersections [Schaber, 1982; Schaber et al., 1992; Senske et al., 1992].

High-emissivity volcanic peaks at high elevations combined with spatially related low-emissivity plains domes have been interpreted to indicate relatively recent volcanic activity [Robinson and Wood, 1993]. Sites of such activity occur in the Beta-Atla-Themis region, which has also been described as having the highest density of volcanic landforms on Venus [Head et al., 1992, Figure 11]. Three of the larger shield volcanoes (Sapas, Maat, and Ozza Montes) in Atla Regio are grouped together and are closely associated with five embayed craters (the densest concentration on the planet) (Figure 20). Maat Mons is thought to have been the most recently active [Robinson and Wood, 1993]. Thus this general region, at the intersection of the Themis-Atla and Aphrodite-Beta tectonic belts, may have been the site of the most recent volcanic activity on Venus. Most of the embayed craters on Venus probably were flooded after global resurfacing, but some of them could have been flooded at the tail end of this event, depending on how rapidly global-scale resurfacing declined.

About $70 \%$ of all heavily fractured craters, $49 \%$ of all slightly fractured craters, and $45.5 \%$ of all volcanically embayed craters lie within the $33.3 \%$ of Venus' surface bordered by latitude $30^{\circ} \mathrm{N}$ and $30^{\circ} \mathrm{S}$, longitude $60^{\circ}$ and $300^{\circ}$ (Table 1; Figure 7). Thirty-two percent of all pristine impact craters on Venus lie within this region (Figure 7a), which also includes most of the major tectonic belts described above (Figure 1). Similarly, $20.5 \%$ of all slightly fractured craters and $18.2 \%$ of all heavily fractured craters are located within the $15 \%$ of Venus' surface lying between $45^{\circ}$ and $90^{\circ} \mathrm{N}$ latitude (including Ishtar Terra). Given that the total crater population is statistically random, these moderate concentrations of fractured and embayed craters (Figures $7 b-7 d$ ) may be significant and indicative of some level of tectonic and volcanic activity in these regions following the end of the last global resurfacing event. However, it must be kept in mind that these craters are simply fractured and/or embayed and that very few have been subjected to tectonic disruption, complete burial, and subsequent removal from the surface. Total crater obliteration, however, must have occurred repeatedly during the global resurfacing event. As indicated by the Monte Carlo simulations described above, only 4-6\% of the planet's surface may have been resurfaced and only a few tens of craters destroyed over the past $300 \mathrm{~m} . \mathrm{y}$.

With the sole exception of the crater Balch on the Beta Regio rift zone $\left(29.95^{\circ} \mathrm{N}, 282.9^{\circ} \mathrm{E}\right)$, the absence of intensely disrupted craters within local and global-scale fracture belts and tesserae suggests that these tectonic terrains continued to be the focus of comparatively minor geologic activity following the end of the last global resurfacing event. Such recent surface fracturing is very likely the result of the direct coupling of mantle convective forces to the surface, even to the present time [Phillips, 1990]. As discussed by Schaber 


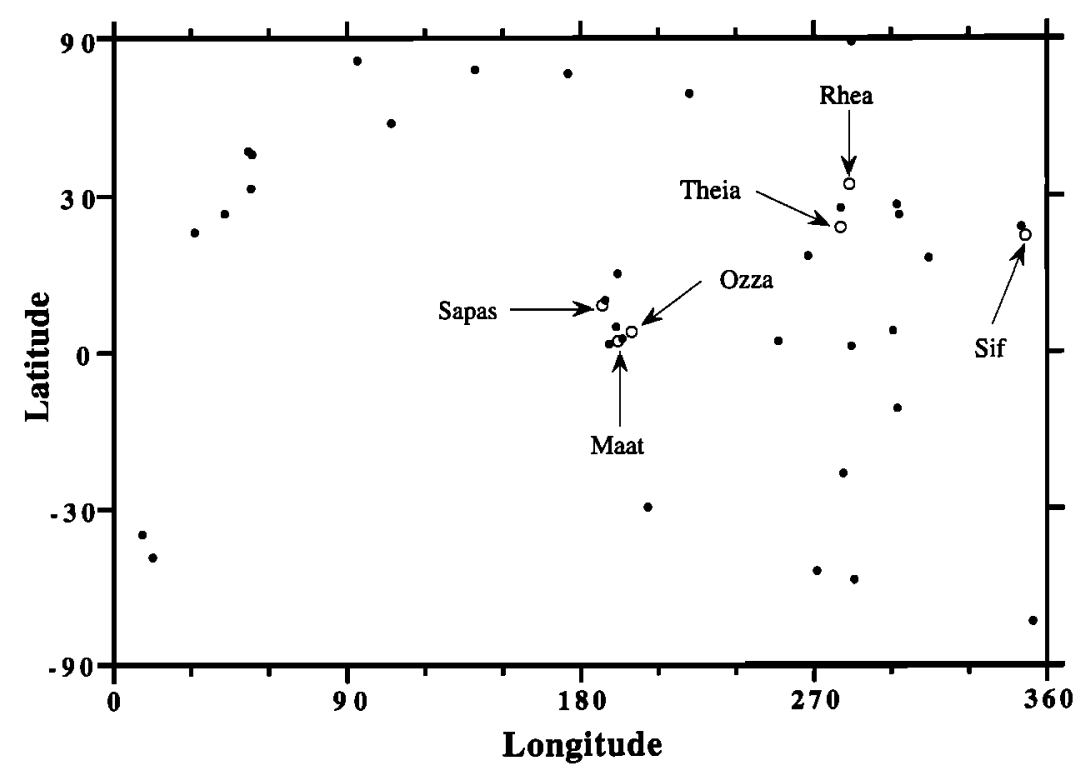

Figure 20. Map showing the distribution of embayed craters (solid circles) and the volcanoes (open circles) thought to have experienced recent activity (volcanic data from Robinson and Wood [1993]).

[1982], Schaber et al. [1992], and above, we agree with Basilevsky [1993] that there has been recent rifting and associated volcanism in Atla Regio, but we strongly disagree that the present level of geologic activity supports the equilibrium model of Phillips et al. [1992] or can explain the observed crater population.

Venus shows many signs of compressive stresses in the form of ridge belts, marginal to tesserae blocks, and wrinkle ridges on the plains (especially in the southern hemisphere). However, only three craters $(0.3 \%)$ are clearly traversed by compressive structures. This strongly indicates that most of the observed compression was part of the global resurfacing event (possibly late) and that lateral movement of the crust on a global scale has since been negligible.

Impact crater degradation on Venus is unlike that observed on any other planet or satellite. Other than the diffusion or removal of impact-related, thin crater halo or parabolic deposits, and darkening of the crater floor deposits, there is no obvious systematic process of degradation and obliteration of craters on Venus, despite suggestions to the contrary [Izenberg et al., 1993b]. Modification of impact craters on Venus is caused almost entirely by tectonism and volcanism. As discussed by Schaber et al. [1992] and reiterated above, the location of a crater on Venus is the dominant factor in how long the crater will exist and how and to what degree the crater is modified. Craters that are highly fractured or lava embayed and occur along the major fracture belts, may be the same age as the most pristine craters on the plains. On present-day Venus, considering the lack of other crater degradational processes of any significance (e.g., impact gardening or water erosion), a crater's geologic future depends solely on whether it formed in an area that will be geologically quiet thereafter. The rate and style of degradation and obliteration vary from region to region. With time, more craters will be degraded and some will be obliterated, but the rate at which new craters form will far exceed the rate at which they are destroyed under the present style and rate of geologic activity. The successive stages of crater degradation in specific regions of Venus, e.g., the fracture belts, can be addressed with further analysis of the Magellan data.

\section{Tesserae Versus Nontesserae}

Based on a study of 915 craters on $96 \%$ of the surface, Ivanov and Basilevsky [1993] reported that the crater density for craters $\geq 16 \mathrm{~km}$ in diameter is 1.4 times higher on tesserae than on all other terrains, but that it is lower on tesserae than other terrains at diameters $<16 \mathrm{~km}$. They interpreted this to mean that there has been an observational loss of small craters on tesserae due to the difficulty of recognizing them, and that the tesserae are on average $40 \%$ older than the plains. The results of our independent measurement of impact crater densities on tesserae (Tables 3 and 4) generally agree with those of Ivanov and Basilevsky [1993]. The tesserae have a population of 78 recognized craters. Considering the 932 craters on $98 \%$ of the planet's surface, we find that about $9.5 \%$ of those $\geq 35-\mathrm{km}$ diameter, $10.5 \%$ of those $\geq 20 \mathrm{~km}$, and $11 \%$ of those $\geq 16 \mathrm{~km}$ are on tesserae (Table 3 ). These percentages are only slightly above the $8.3 \%$ of the planet's surface reported to be occupied by tesserae (M. A. Ivanov and J. W. Head, Tessera terrain on Venus: A survey of the global distribution, characteristics, and relation to surrounding units from Magellan data, submitted to Journal of Geophysical Research, 1993; hereinafter referred to as submitted paper). For craters $\geq 35$, $\geq 20$, and $\geq 16 \mathrm{~km}$, the tesserae are about $1.1,1.3$, and 1.3 times more cratered, respectively, than the average planet if the $8.3 \%$ total area reported for tesserae is correct. Ivanov and Basilevsky [1993] caution that the statistical reliability of this conclusion is a strong function $\left(s=N^{1 / 2}\right.$ ) of the amount of craters in the size interval, and that the conclusion depends on the mode of data presentation. It is probably no coincidence that the percentage of craters on tesserae $(8.3 \%)$ is exactly the same as the percentage of Venus covered by tesserae. We iterate that the impact crater population cannot be distinguished from both a spatially and hypsometrically random distribu- 
Table 3. Craters on Tesserae Compared With Entire Surface of Venus

\begin{tabular}{|c|c|c|c|c|}
\hline \multirow{2}{*}{$\begin{array}{l}\text { Modification } \\
\text { Class }\end{array}$} & \multicolumn{2}{|c|}{$\begin{array}{l}\text { Craters on } \\
\text { Tesserae }\end{array}$} & \multicolumn{2}{|c|}{ Craters on Venus } \\
\hline & Number & Percent & Number & Percent \\
\hline \multicolumn{5}{|c|}{ All Craters } \\
\hline Pristine & 57 & 73.08 & 785 & 84.23 \\
\hline Slightly fractured & 15 & 19.23 & 78 & 8.37 \\
\hline Heavily fractured & $\begin{array}{c}6 \\
>35-k m\end{array}$ & $\begin{array}{c}7.69 \\
\text { Diameter }\end{array}$ & 33 & 3.54 \\
\hline Pristine & 14 & 9.52 & 113 & 12.12 \\
\hline Slightly fractured & 2 & 2.56 & 15 & 1.62 \\
\hline Heavily fractured & 1 & 1.28 & 8 & 0.85 \\
\hline \multicolumn{5}{|c|}{$>20-\mathrm{km}$ Diameter } \\
\hline Pristine & 28 & 35.9 & 267 & 28.65 \\
\hline Slightly fractured & 4 & 5.13 & 33 & 3.54 \\
\hline Heavily fractured & 4 & 5.13 & 24 & 2.58 \\
\hline \multicolumn{5}{|c|}{$>16-\mathrm{km}$ Diameter } \\
\hline Pristine & 34 & 43.59 & 341 & 36.59 \\
\hline Slightly fractured & 7 & 8.97 & 39 & 4.18 \\
\hline Heavily fractired & 6 & 7.69 & 28 & 3 \\
\hline \multicolumn{5}{|c|}{$<16-\mathrm{km}$ Diameter } \\
\hline Pristine & 19 & 24.36 & 452 & 48.5 \\
\hline Slightly fractured & 8 & 10.26 & 39 & 4.18 \\
\hline Heavily fractured & 1 & 1.28 & 6 & 0.64 \\
\hline
\end{tabular}

tion with stochastic variations, and therefore it is not possible to determine relative or absolute ages from crater densities. This is especially true for relatively small areas with few craters.

We performed a chi-square test of the data in Table 4 to determine if there is a statistically significant difference between the number of craters on tesserae compared with that expected on the other parts of the planet. The test yields a $P$ value of 0.1366 (Table 4). This value is well above the upper limit of 0.05 for a statistically different population. Therefore the density of craters on tesserae compared with all other terrains is not statistically different from that expected for a random population. The major difference between the number of tesserae craters and that expected occurs only in one size interval $(16-22.6 \mathrm{~km})$, where the normalized difference $\left([O-E]^{2} / E\right)$ is 4.3 (Table 4). At all other diameters the normalized differences are less than 2.6. This suggests that the difference in the 16- to $22.6-\mathrm{km}$ size interval is a stochastic effect, similar to that discussed earlier for the volcanic versus the sparse volcanic areas. Furthermore, the apparent paucity of craters $<16-\mathrm{km}$ diameter on tesserae is well within the statistical uncertainty and may not be due to any significant observation loss (Table 4).

Although the tesserae are clearly onlapped regionally by lava plains and are probably older rock units than the average plains, it cannot be stated that the tesserae are older than the rest of the planet. Statistically they are the same average surface age (crater retention age). It appears that the cratering record on the tesserae was nearly or completely reset, dominantly by tectonism, during the global resurfacing event(s) while the rest of the planet was being resurfaced dominantly by volcanism. However, at least some highly disrupted circular features on this terrain may be impact craters that survived the last global resurfacing event.

For craters $\geq 16 \mathrm{~km}$ in diameter on tesserae, 9\% are slightly fractured and $7.7 \%$ are heavily fractured (Table 3 ). These percentages represent excesses of 2.1 times greater density for slightly fractured craters, and 2.6 times greater density for heavily fractured craters, than the planet as a whole for these crater sizes. The distributions of fractured and pristine craters of various sizes are listed in Table 3. The results described above indicate that tesserae craters have been fractured at a rate that is no more than about twice that of the average planet since global resurfacing ended about 300 m.y. ago (see Tables 1 and 3). However, there is no

Table 4. Statistics for Craters on Tesserae

\begin{tabular}{ccccc}
\hline $\begin{array}{c}\text { Diameter } \\
\text { Range, } \\
\text { km }\end{array}$ & $\begin{array}{c}\text { Mean } \\
\text { Diameter, } \\
\text { km }\end{array}$ & $\begin{array}{c}\text { Number } \\
\text { Observed }\end{array}$ & $\begin{array}{c}\text { Number } \\
\text { Expected }\end{array}$ & $(O-E)^{2} / E$ \\
\hline $1.4-2$ & 1.68 & 0 & 0.498 & 0.50 \\
$2-2.8$ & 2.38 & 2 & 1.743 & 0.04 \\
$2.8-4$ & 3.36 & 0 & 2.573 & 2.57 \\
$4-5.6$ & 4.75 & 3 & 6.308 & 1.73 \\
$5.6-8$ & 6.72 & 5 & 8.217 & 1.26 \\
$8-11.3$ & 9.51 & 11 & 11.62 & 0.03 \\
$11.3-16$ & 13.45 & 10 & 10.79 & 0.06 \\
$16-22.6$ & 19.02 & 19 & 11.869 & 1.28 \\
$22.6-32$ & 26.91 & 14 & 10.209 & 1.00 \\
$32-45.2$ & 38.05 & 4 & 6.557 & 2.46 \\
$45.2-64$ & 53.81 & 7 & 3.901 & 0.43 \\
$64-90.5$ & 76.11 & 1 & 1.909 & 2.10 \\
$90.5-128$ & 107.63 & 2 & 0.747 & 17.88 \\
Total & & 78 & & \\
\hline
\end{tabular}

Number expected is $8.3 \%$ (area of tesserae (M.A. Ivanov and J. W. Head, submitted manuscript, 1993)) of total number of craters in size bins shown in Table 1. $P$ value (two upper and two lower size bins combined) $=0.1366 . P$ value (no combined size bins) $=0.134$. The percentage of tesserae craters $(8.3 \%)$ is the same as the percentage of Venus covered by tesserae. 
evidence for extensive crater obliteration on the tesserae since that time.

\section{Global Resurfacing Mechanisms}

Several thermal evolution models have been proposed to account for global resurfacing on Venus. One model suggests that because of the high surface temperatures, an oscillatory convective regime occurred throughout much of Venusian history and resulted in episodic global resurfacing, planetary cooling, and a change in the convective regime from oscillatory to quasi-steady state [Arkani-Hamed and Toksoz, 1984; Arkani-Hamed, 1993; Arkani-Hamed et al., 1993]. Hsui [1993] also finds that because of elevated surface temperatures on Venus the resulting rheological effects may enhance its cooling rate. In the Arkani-Hamed/Toksoz model the high surface temperature of Venus results in elevated temperatures and reduced strength of the lithosphere, which produces a deformable layer capable of being incorporated in mantle circulation. The convection is oscillatory with avalanche-type properties that induce increases in the surface heat flux. In contrast, the low surface temperatures on Earth have resulted in an oceanic lithosphere that is more difficult to subduct. This, combined with a continental lithosphere that is buoyant, has led to a semirigid cap on Earth's convecting mantle that has surpressed cooling. Venus cools rapidly because the mobility of its outer layer allows mantle material to approach the surface more readily and cool more efficiently. The rapid cooling leads to core solidification, even if there is enough sulfur to reduce the melting temperature by as much as $500^{\circ} \mathrm{C}$. As a result of core solidification, the magnetic field terminates, and cooling of the mantle increases the viscosity, causing the convective regime to change. Thus, as Venus cools, the Rayleigh number decreases, changing the convection from oscillatory to quasi-steady state motion. According to the model of Arkani-Hamed and Toksoz [1984], this occurs about 500 m.y. ago, when Venus' lithosphere changes from a recycling to a one-plate lithosphere with a much lower level of localized hot-spot volcanism and dominantly tensional tectonics.

Turcotte [1993] has also proposed an episodic recycling of the crust. In this model a stable, thickening lithosphere lacking plate tectonics results in less heat flux at the surface and an increase in the mean interior temperature at a rate of about $100 \mathrm{~K} / \mathrm{b}$.y. Although this increase is relatively small, it is likely to lead to more vigorous mantle convection that triggers rapid plate tectonics and rapid resurfacing. As the planet cools, the lithosphere stabilizes and thickens by conduction, and the process begins again.

Another possible global resurfacing mechanism is a consequence of chemical differentiation in a one-plate planet [Parmentier and Hess, 1992]. In this model, partial melting produces new crust and creates a compositionally buoyant residual mantle. On Earth, subducted cold plates may mix this depleted mantle with the main mantle, but on Venus it accumulates at the top of the mantle. With time, less depleted mantle with less positive buoyancy is added, and eventually, the negative thermal buoyancy of the layer exceeds its positive compositional buoyancy. Crustal recycling and global resurfacing then occur as the dense eclogite layer that formed at the base sinks through the depleted mantle layer to mix with the deeper mantle. According to this model, the process occurs repeatedly, with a period of 300-500 m.y.

Steinbach and Yuen [1992] and Weinstein [1993] have studied the effect of phase transitions, e.g., olivine to spinel and spinel to perovskite, on standard numerical models of mantle convection. They found that phase transitions can cause "catastrophic" convective episodes similar to those proposed for Venus by Parmentier and Hess [1992]. According to Steinbach and Yuen [1992], the cooling of Venus and the consequent decrease in the Rayleigh number may result in a transition from layered convection to whole-mantle convection, causing a global resurfacing event.

Herrick and Parmentier [1994] find that episodic largescale overturn of two-layer mantles in the Earth, Venus, and Mars could lead to major resurfacing events on Venus and Mars, and the initiation of new plate tectonic cycles on Earth. In their thermal model, overturn initially occurs when thermal expansion of a chemically denser lower mantle offsets the compositional density difference between the layers and reverses the relative sense of buoyancy. Their thermal evolution calculations suggest that large-scale overturn occurs cyclically with a well-defined period that depends mostly on the viscosity of the lower mantle. Such mantle overturns could account for global resurfacing events on Venus.

Thus there appear to be several mechanisms that could produce episodic global resurfacing events on Venus. In the model of Arkani-Hamed et al. [1993] the recycling of Venus is finished, whereas in the other models, Venus is currently between global resurfacing events.

\section{Episodic Events on the Earth and Mars}

Episodic global or regional resurfacing events may be common on at least the larger terrestrial planets. The Earth appears to have experienced episodic regional enhanced resurfacing events ("superplumes") resulting from accelerated mantle convection and heat loss [Garzanti, 1993, and references therein]. These events are recognized by (1) enhanced alkalic basalt production and oceanic ridge spreading rates, (2) anomalous sedimentary conditions resulting from warm "greenhouse" climates, and eustatic rise, sluggish circulation, and poor ventilation of the oceans, (3) stressed biota, and (4) anomalously long periods between magnetic reversals [Garzanti, 1993]. They probably produced the "large igneous provinces" characterized by the Ontong-Java and Kerguelen-Broken Ridge oceanic plateaus, the North Atlantic volcanic passive margin, and the Deccan and Columbia River continental flood basalts [Coffin and Eldholm, 1994]. Such events may have occurred in the Late Devonian, Pennsylvanian-Permian, Late Triassic, Middle Jurassic, mid-Cretaceous, and Paleocene.

The best documented event occurred during the midCretaceous between 80 and $120 \mathrm{~m} . \mathrm{y}$. ago, lasted about 40 m.y., and resulted in a 50-75\% enhancement in the resurfacing rate at spreading centers [Larson, 1991a, b]. The beginning and end of the event were abrupt; the first $20 \mathrm{~m}$.y. experienced peak ocean crustal production rates $\left(\sim 32 \mathrm{~km}^{3} /\right.$ yr). The event produced vast basalt plateaus such as the Ontong-Java plateau in the Pacific $\left(1.01 \times 10^{8} \mathrm{~km}^{3}\right)$. Plateau basalt production reached a high of about $6 \mathrm{~km}^{3} / \mathrm{yr}$ during this time (the "normal" value is about $2 \mathrm{~km}^{3} / \mathrm{yr}$ ). The event may have added 3.7-14.7 times the preindustrial $\mathrm{CO}_{2}$ con- 
tent $(285 \mathrm{ppm})$ to the atmosphere and caused a greenhouse warming of $2.8^{\circ}-7.7^{\circ} \mathrm{C}$ above the present global average [Caldeira and Rampino, 1991]. This resurfacing event coincided with the long Cretaceous interval of normal magnetic polarity. The pulse is attributed to a "superplume" in the Pacific Ocean basin with minimum areal dimensions constituting about $12 \%$ of Earth's surface.

Although much less certain, there is some evidence that episodic regional resurfacing events may also have occurred on Mars. The thermal evolution model of Herrick and Parmentier [1994] discussed previously suggests that Mars may have experienced episodic large-scale overturn of its mantle with periods of the order of $10^{7}-10^{9}$ years if lower mantle viscosities were $10^{21}-10^{23} \mathrm{~Pa}$ s. Such events could have led to periods of enhanced volcanism. Other thermal history models of Mars suggest that oscillations in the convective regime of Mars may have occurred [Schubert et al., 1990]. Magmatic activity was apparently most intense during Hesperian and Early Amazonian time [Greeley and Schneid, 1991]. The great outflow channels that resulted from violent floods show multiple episodes of catastrophic subsurface water release that also cover the same range of ages [Tanaka and Chapman, 1990, 1992]. Baker et al. [1991] proposed that volcanism triggered the catastrophic release of water that formed episodic oceans in the northern plains and ice sheets in the polar regions [Kargel and Strom, 1992]. Perhaps mantle overturn and enhanced magmatism were the cause of these outflow episodes. Although this constitutes only circumstantial evidence for episodic internal activity on Mars, it is highly suggestive given the probability of oscillatory mantle activity (convective and/or overturn) on Earth, Venus, and Mars.

\section{Conclusions}

The cratering record on Venus consists of 1333 craters and crater-related features. It is very unusual because, among other things, the craters have a spatially and hypsometrically random distribution and they are mostly very well preserved. The eolian erosion rate of unconsolidated to semiconsolidated material is extremely low, about $23-0.3 \mathrm{~cm} /$ m.y., too low to have significantly modified the solid surface. This, together with the lack of water, the low level of volcanism and tectonism, and the relative youth of the surface, explains why the surface features are so well preserved.

The entire surface of Venus imaged by Magellan has been strongly affected by either intense volcanic activity or severe tectonic deformation. However, only about $2.5 \%$ of the impact craters and crater-related features have been embayed by lava, and only about $12 \%$ of the craters have been fractured. This is truly remarkable, seen on only one other body in the Solar System that has experienced extensive volcanic or tectonic activity [Smith et al., 1989]. That body is Neptune's satellite Triton, all of whose craters are pristine. Even there the crater distribution is nonrandom because of the leading/trailing asymmetry [Smith et al., 1989; Strom et al., 1990; Croft et al., 1994]. The pristine nature of the craters on Triton has also been interpreted to be the result of a global resurfacing event that erased the preexisting cratering record, followed by solidification and the accumulation of the present crater population. On Triton the global resurfacing was probably caused by tidal heating during circularization of the orbit following capture [Goldreich et al., 1989].

The most likely explanation of the somewhat similar cratering record on Venus is that the planet also experienced a global resurfacing event about $300 \mathrm{~m}$.y. ago, followed by greatly reduced tectonism and volcanism, and the accumulation of the impact craters seen today. The event probably lasted tens of millions of years or more but may have ended abruptly (<10 m.y.). Volcanism and tectonism continued at a much lower level and are probably active today. The global resurfacing events may have added significant quantities of $\mathrm{CO}_{2}$ to the atmosphere.

Monte Carlo simulations suggest that about $4-6 \%$ of the entire planet has been volcanically resurfaced since the global event and that the lava production rate was about $0.01-0.15 \mathrm{~km}^{3} / \mathrm{yr}$ during the past $300 \mathrm{~m}$.y. This is about $3-33$ times less than the current rate of intraplate volcanism on Earth. The most recent volcanism on Venus has occurred in the Beta-Atla-Themis region [Head et al., 1992; Robinson and Wood, 1993], especially in association with shield construction at the two intersections of the Aphrodite-Beta, Themis-Atla, and Phoebe-Beta tectonic belts at Atla Regio and Beta Mons [Schaber, 1982]. This is where most of the volcanic landforms and embayed craters are concentrated and where high emissivities at high elevations on several volcanoes suggest recent activity.

The most recent tectonism (since the end of the resurfacing event) has occurred along the major equatorial fracture belts between latitudes $30^{\circ} \mathrm{N}$ and $30^{\circ} \mathrm{S}$, longitudes $60^{\circ}-300^{\circ} \mathrm{E}$, where heavily fractured craters are concentrated at a level about twice that of the global average for this type of crater. Fifteen percent of the lava-embayed craters are also concentrated in this region, around the bases of Sapas, Ozza, and Maat Montes, and in Atla Regio. Although our crater counts on tesserae are similar to those of Ivanov and Basilevsky [1993], statistical tests of the data indicate that there is no statistically significant difference between the number of craters on tesserae and that on other parts of the planet. This indicates that the average surface age of the tesserae is the same as the average age of the surface as a whole and that any observational loss of small craters on tesserae is not statistically significant.

The continuation of some level of limited (primarily extensional) tectonism and localized volcanic activity on Venus over about the past $300 \mathrm{~m}$.y. is an integral part of the global resurfacing model. We have shown, however, that neither the present level and style of geologic activity on Venus nor any form of equilibrium resurfacing [Phillips et al., 1992] could have produced the observed global cratering record.

One would expect some level of geologic activity on a planet the size of Venus over the past $300 \mathrm{~m}$. y. The global resurfacing model, originally reported by Schaber et al. [1992], proposed that geologic activity (especially volcanism) declined significantly and over a geologically short time on the scale of cratering events. This recent activity has simply been different and at a different scale from earlier activity, when the entire record of the early heavy bombardment and much of the subsequent record of bombardment were erased from the surface by massive volcanism and tectonic activity.

The Earth, and possibly Mars, have also experienced periodic enhanced resurfacing events. Unlike those on Ve- 
nus, these events were regional in scope, but they had global consequences. The low surface temperatures on Earth have resulted in an oceanic lithosphere that is more difficult to subduct. This, combined with a continental lithosphere that is buoyant, has led to a semirigid cap on Earth's convecting mantle that prevents global recycling and that suppresses cooling. Thus oscillating mantle convection produces regional events with global consequences. On Mars, similar episodic events may have led to enhanced basalt effusion and may have triggered the catastrophic floods that caused the outflow channels. Therefore at least the larger terrestrial planets appear to have experienced oscillatory convection that has led to enhanced basaltic volcanism and other global consequences. On Mars these oscillations probably ceased over 1 b.y. ago, whereas on Venus they may have terminated about 300-500 m.y. ago. On Earth they still continue.

Acknowledgments. The authors wish to thank Tammy Becker and Kay Edwards of the USGS, Flagstaff, for providing data processing support. We also thank Joel Russell and John Chadwick for aiding in the collection of the crater database, and Doris Weir for editing the manuscript. We especially thank Scott Emerson of the Department of Statistics at the University of Arizona, and Maria Banks (NASA Space Grant student) for their help with the statistical analyses. We also thank the following students at the University of Arizona for their help in identifying and classifying craters on the tesserae: Joann Vasquez (NASA Space Grant student), Andrew Papanikolas, Dylan Krider, and Jayln Richardson. We also thank N. Izenberg for providing us with the list of craters and parabolic features he considers to have been embayed. The reviews of this paper by $R$. Phillips and an anonymous reviewer were very helpful in revising the final manuscript. This research was partly supported by NASA grant NAGW-3705 (R.G.S.), and NASA grants W15,814 and WO8777 (G.G.S.). D. D. Dawson was supported by a National Science Foundation Fellowship.

\section{References}

Arkani-Hamed, J., On the tectonics of Venus, Phys. Earth Planet. Inter., 76, 75-96, 1993.

Arkani-Hamed, J., and M. N. Toksoz, Thermal evolution of Venus, Phys. Earth Planet. Inter., 34, 232-250, 1984.

Arkani-Hamed, J., G. G. Schaber, and R. G. Strom, Constraints on the thermal evolution of Venus inferred from Magellan data, $J$. Geophys. Res., 98(E3), 5309-5315, 1993.

Asimow, P. D., and J. A. Wood, Fluid outflows from Venus impact craters: Analysis from Magellan data, J. Geophys. Res., 97(E8), 13,643-13,665, 1992.

Baker, V. R., R. G. Strom, V. C. Gulick, J. S. Kargel, G. Komatsu, and V.S. Kale, Ancient oceans, ice sheets and the hydrological cycle on Mars, Nature, 352, 589-594, 1991.

Baker, V. R., G. Komatsu, T. J. Parker, V. C. Gulick, J. S. Kargel, and J. S. Lewis, Channels and valleys on Venus: Preliminary analysis of Magellan data, J. Geophys. Res., 97(E8), 13,42113,444, 1992.

Basaltic Volcanism Study Project, Basaltic Volcanism on the Terrestrial Planets, 1285 pp., Pergamon, New York, 1981.

Basilevsky, A. T., Age of rifting and associated volcanism in Atla Regio, Venus, Geophys. Res. Lett., 20, 883-886, 1993.

Bullock, M. A., D. H. Grinspoon, and J. W. Head, Venus resurfacing rates: Constraints provided by 3-D Monte Carlo simulations, Geophys. Res. Lett., 20, 2147-2152, 1993.

Caldeira, K., and M. R. Rampino, The mid-Cretaceous super plume, carbon dioxide and global warming, Geophys. Res. Lett. 18(6), 987-990, 1991.

Campbell, D. M., N. J. S. Stacy, W. I. Newman, R. E. Arvidon, E. M. Jones, G. S. Musser, A. Y. Roper, and C. Schaller, Magellan observations of extended impact crater related features on the surface of Venus, J. Geophys. Res., 97(E10), 16,24916,277, 1992.

Chadwick, D. J., and G. G. Schaber, Impact crater outflows on
Venus: Morphology and emplacement mechanisms, J. Geophys. Res., 98(E11), 20,891-20,902, 1993.

Chadwick, D. J., and G. G. Schaber, Evidence for episodic tectonic construction of Ovda Regio, Venus (abstract), Lunar Planet. Sci., 25, 229-230, 1994.

Chyba, C. F., P. J. Thomas, and K. J. Zahnle, The 1908 Tunguska explosion: Atmospheric disruption of a stony asteroid, Nature, $361,40-44,1993$.

Coffin, M. F., and O. Eldholm, Large igneous provinces: Crustal structure, dimensions, and external consequences, Rev. Geophys., 32, 1-36, 1994.

Crater Analysis Techniques Working Group, Standard techniques for analysis of crater size-frequency data, lcarus, 37, 467-474, 1979.

Crisp, J. A., Rates of magma emplacement and volcanic output, $J$. Volcanol. Geotherm. Res., 20, 177-211, 1984.

Croft, S. K., J. L. Kargel, R. Kirk, J. M. Moore, P. M. Schenk, and R. G. Strom, Geology of Triton, in Neptune, University of Arizona Press, Tucson, 107, 84-97, 1994.

Garzanti, E., Himalayan ironstones, "superplumes," and the breakup of Gondwana, Geology, 21, 105-108, 1993.

Goldreich, P., N. Murray, P. Y. Longaretti, and D. Banfield, Neptune's story, Science, 245, 500, 1989.

Greeley, R., and B. D. Schneid, Magma generation on Mars: Amounts, rates and comparisons with Earth, Moon, and Venus, Science, 254, 996-998, 1991.

Greenberg, R., M. C. Nolan, W. F. Bottke, R. A. Kolvoord, and J. Veverka, Collisional history of Gaspra, Icarus, 107, 84-97, 1994. Grinspoon, D. H., Implications of the high D/H ratio for the sources of water in Venus' atmosphere, Nature, 363, 428-431, 1993.

Head, J. W., L. S. Crumpler, and J. C. Aubele, Venus volcanism: Classification of volcanic features and structures, associations, and global distribution from Magellan data, J. Geophys. Res., 97(E8), 13,153-13,197, 1992.

Herrick, D. L., and E. M. Parmentier, Episodic large-scale overturn of two-layer mantles in terrestrial planets, J. Geophys. Res., 99(E1), 2053-2062, 1994.

Herrick, R. R., The three ages of Venus (abstract), Lunar Planet. Sci., XXIV, 645-646, 1993.

Hills, J. G., and M. P. Goda, The fragmentation of small asteroids in the atmosphere, Astron. J., 105(3), 1114-1144, 1993.

Holcomb, R. T., Eruptive history and long-term behavior of Kilauea Volcano, Volcanism in Hawaii, U.S. Geol. Surv. Prof. Pap., 1350, 261-350, 1987.

Hsui, A. T., Surface temperature, mantle convection, and thermal history of Venus, Eos Trans. AGU, 74(43), Fall Meeting suppl., $378,1993$.

Ivanov, B. A., I. V. Nemchinov, V. A. Svetsov, A. A. Provalov, V. M. Khazins, and R. J. Phillips, Impact cratering on Venus: Physical and mechanical models, J. Geophys. Res., 97(E10), 16,167-16,181, 1992.

Ivanov, M. A., and A. T. Basilevsky, Density and morphology of impact craters on tessera terrain, Venus, Geophys. Res. Lett., 20, 2579-2582, 1993.

Izenberg, N. R., R. J. Phillips, and R. E. Arvidson, Models for crater degradation and secular decay of resurfacing rates on Venus, Eos Trans. AGU, 74(43), Fall Meeting suppl., 379, 1993a.

Izenberg, N. R., R. E. Arvidson, and R. J. Phillips, A first-order model for impact crater degradation on Venus (abstract), Lunar Planet. Sci., XXIV, 703-704, 1993 b.

Kargel, J. S., and R. G. Strom, Ancient glaciation on Mars, Geology, 62, 310-316, 1992.

Komatsu, G., V. R. Baker, and V. C. Gulick, Venusian channels and valleys: Distribution and volcanological implications, Icarus, 102, 1-25, 1993.

Larson, R. L., Latest pulse of Earth: Evidence for a mid-Cretaceous superplume, Geology, 19, 547-550, 1991a.

Larson, R. L., Geological consequences of superplumes, Geology, 19, 963-966, 1991b.

Masursky, H., E. Eliason, P. G. Ford, G. E. McGill, G. H. Pettengill, G. G. Schaber, and G. Schubert, Pioneer Venus radar results: Geology from images and altimetry, J. Geophys. Res., 85, 8232-8260, 1980.

McGill, G. E., S. J. Steenstrup, C. Barton, and P. G. Ford, Continental rifting and the origin of Beta Regio, Venus, Geophys. Res. Lett., 8, 737-740, 1981. 
Parmentier, E. M., and P. C. Hess, Chemical differentiation of a convecting planetary interior: Consequences for a one plate planet such as Venus, Geophys. Res. Lett., 19, 2015-2018, 1992.

Phillips, R. J., Convection-driven tectonics on Venus, J. Geophys. Res., 95, 1301-1316, 1990.

Phillips, R. J., The age spectrum of the Venusian surface, Eos Trans. $A G U, 74(16)$, Spring Meeting suppl., 187, 1993.

Phillips, R. J., R. F. Raubertas, R. E. Arvidson, I. C. Sarkar, R. R. Herrick, N. Izenberg, and R. E. Grimm, Impact craters and Venus resurfacing history, J. Geophys. Res., 97(E10), 15,923$15,948,1992$.

Price, M. H., and J. Suppe, Tectonism, volcanism, and impact craters: Implications for the resurfacing of Venus, Eos Trans. $A G U, 74(43)$, Fall Meeting suppl., 379, 1993.

Robinson, C. A., and J. A. Wood, Recent activity on Venus: Evidence from radiothermal emissivity measurements, Icarus, $102,26-39,1993$

Schaber, G. G., Venus: Limited extension and volcanism along zones of lithospheric weakness, Geophys. Res. Lett., 9, 499-502, 1982.

Schaber, G. G., et al., Geology and distribution of impact craters on Venus: What are they telling us?, J. Geophys. Res., 97(E8), 13,257-13,301, 1992.

Schubert, G., D. Bercovici, and G. A. Glatzmaier, Mantle dynamics in Mars and Venus, J. Geophys. Res., 95, 14,105-14,129, 1990.

Schultz, P. H., Atmospheric effects on ejecta emplacement and crater formation on Venus from Magellan data, J. Geophys. Res., - 97(E10), 16,183-16,248, 1992.

Schultz, P. H., Searching for ancient Venus (abstract), Lunar Planet. Sci., XXIV, 1255-1256, 1993.

Seiff, A., Thermal structure of the atmosphere of Venus, in Venus, edited by D. M. Hunten et al., pp. 215-279, University of Arizona Press, Tucson, 1983.

Senske, D. A., G. G. Schaber, and E. R. Stofan, Regional topographic rises on Venus: Geology of western Eistla Regio and comparison to Beta Regio and Atla Regio, J. Geophys. Res., 97(E8), 13,395-13,420, 1992.

Shoemaker, E. M., R. F. Wolfe, and C. S. Shoemaker, Asteroid flux and impact cratering rate on Venus, Reports of Planetary Geology and Geophysics Program-1990, NASA Tech. Memo., TM-4300, 389-390, 1991.

Smith, B. A., et al., Voyager 2 at Neptune: Imaging science results, Science, 246, 1422-1449, 1989.
Solomon, S. C., The geophysics of Venus, Phys. Today, 48-55, 1993a.

Solomon, S. C., A tectonic resurfacing model for Venus, Lunar Planet. Sci., XXIV, 1831-1832, 1993b.

Steinbach, V., and D. A. Yuen, The effects of multiple phase transitions on Venusian mantle convection, Geophys. Res. Lett., 19, 2243-2246, 1992.

Strom, R. G., Parabolic features and the erosional rate on Venus (abstract), Lunar Planet. Sci., XXIV, 1371-1372, 1993.

Strom, R. G., S. K. Croft, and J. M. Boyce, The impact cratering record on Triton, Science, 250, 437-439, 1990.

Strom, R. G., S. K. Croft, and N. G. Barlow, The Martian impact cratering record, in Mars, edited by H. H. Kieffer et al., pp. 383-423, University of Arizona Press, Tucson, 1992.

Tanaka, K. L., and M. G. Chapman, The relation of catastrophic flooding of Mangala Valles, Mars, to faulting of Memnonia Fossae and Tharsis volcanism, J. Geophys. Res., 95(B9), 14,315-14,323, 1990.

Tanaka, K. L., and M. G. Chapman, Kasei Valles, Mars: Interpretation of canyon materials and flood sources, Proc. Lunar Planet. Sci. Conf., 22, 73-83, 1992.

Turcotte, D. L., An episodic hypothesis for Venusian tectonics, $J$. Geophys. Res., 98, 17,061-17,068, 1993.

Vervack, R. J., and H. J. Melosh, Wind interaction with falling ejecta: Origin of the parabolic features on Venus, Geophys. Res. Lett., 19, 525-528, 1992.

Weinstein, S. A., Catastrophic overturns of the Earth's mantle driven by multiple phase changes and internal heat generation, Geophys. Res. Lett., 20, 102-104, 1993.

Wilhelms, D. E., The geologic history of the Moon, U.S. Geol. Surv. Prof. Pap., 1348, 1987.

Zahnle, K. J., Airburst origin of dark shadows on Venus, $J$. Geophys. Res., 97(E6), 10,243-10,255, 1992.

D. D. Dawson and R. G. Strom, Department of Planetary Sciences, University of Arizona, Tucson, AZ 85721.

G. G. Schaber, Branch of Astrogeology, U.S. Geological Survey, Flagstaff, AZ 86001.

(Received August 9, 1993; revised January 19, 1994; accepted February 9, 1994.) 